\title{
Solution Processable Material Derived from Aromatic Triazole, Azomethine and Tris: Preparation and Hole-Buffering Application in Polymer Light-Emitting Diodes
}

\author{
Chih-Yang Lin, Yun Chen* \\ Department of Chemical Engineering, National Cheng Kung University, Taiwan \\ Email: *yunchen@mail.ncku.edu.tw
}

How to cite this paper: Lin, C.-Y. and Chen, Y. (2018) Solution Processable Material Derived from Aromatic Triazole, Azomethine and Tris: Preparation and Hole-Buffering Application in Polymer Light-Emitting Diodes. Journal of Materials Science and Chemical Engineering, 6, 6-28. https://doi.org/10.4236/msce.2018.69002

Received: August 31, 2018

Accepted: September 27, 2018

Published: September 30, 2018

Copyright $\odot 2018$ by authors and Scientific Research Publishing Inc. This work is licensed under the Creative Commons Attribution International License (CC BY 4.0).

http://creativecommons.org/licenses/by/4.0/

\begin{abstract}
This work presents the synthesis of a new hole-buffering material TAZS and its successful application in polymer light-emitting diodes to enhance device performance. The TAZS is composed of aromatic 1,2,4-triazolylcore linked with three trihydroxy tert-butyl terminals via azomethine linkages. The TAZS forms ashomogeneous film deposited by spin-coating process. The HOMO and LUMO levels of TAZS are $-5.23 \mathrm{eV}$ and $-2.40 \mathrm{eV}$, respectively, as estimated from cyclic voltammogram. The current density results of hole-only and electron-only devices confirm strong hole-buffering capability of TAZS layer. Multilayer PLEDs with different thickness of TAZS (ITO/PEDOT: PSS/TAZS (x nm)/SY/ETL/LiF/Al) have been successfully fabricated, using spin-coating process to deposit hole-injecting PEDOT: PSS, TAZS, and emissive SY layers. The PLED with $16 \mathrm{~nm}$ TAZS reveals the optimal device performance, with maximum luminance and maximum current efficiency of $19,046 \mathrm{~cd} / \mathrm{m}^{2}$ and $4.08 \mathrm{~cd} / \mathrm{A}$, respectively, surpassing those without TAZS as HBL $\left(8484 \mathrm{~cd} / \mathrm{m}^{2}, 2.13 \mathrm{~cd} / \mathrm{A}\right)$. The hole-buffering characteristic of TAZS contributes greatly to improved charges' recombination ratio and enhanced emission efficiency.
\end{abstract}

\section{Keywords}

Hole-Buffering, Azomethine, Aromatic Triazole, Tris, Polymer Light-Emitting Diodes, Spin-Coating

\section{Introduction}

Polymer light-emitting diodes (PLEDs) [1] [2] [3] and organic light-emitting 
diodes (OLEDs) [4] [5] [6] have drawn considerable attention due to numerous advantages such as self-luminous, wide view angle, and fast response time. Furthermore, PLEDs can be easily adapted for solution processes such as spin-coating and ink-jet printing which are appropriate processes for the fabrication of large-area and flexible displays [1] [2] [3]. Conversely, OLEDs was conventionally fabricated by thermal evaporation under vacuum, which is more costly and complicated. In general, balanced charge recombination in emission layer (EML) is essential for enhancement of device efficiency and stability. However, for most conjugated organic polymers and compounds applied in PLEDs holes transport more favorably than electrons [7] [8]. Therefore, efficient hole-buffering layer, which slows down hole-transport, is able to improve charge balance in EML. Some hole-buffering materials have been reported, such as copper(II) phthalocyanine (CuPC) and 4,4',4'-tris(N-carbazolyl)-triphenyla-mine (TATC) [9] [10]. They were inserted between hole injection layer and emission layer to reduce hole-transport effectively and improve the device performance [11]. We have prepared a hole-buffering polymer composed of alternating $p$-terphenyl and tetraethylene glycol ether, which effectively balance charges and device efficiency [12].

Formation of Schiff base is a nucleophilic addition of primary amine andaldehyde group, followed with dehydration to form as azomethine $(-\mathrm{CH}=\mathrm{N}-)$. Schiff bases composed of azomethines have been reported during the past two decades as materials for organic optoelectronic application [12]-[19]. The azomethine bond possesses similar isoelectronic characteristics to vinyl bond, giving rise to similar optoelectronic and thermal properties [20] [21] [22]. However, most of the Schiff base derivatives prepared for OLED applications focused on phosphorescent luminescent materials [23] [24] [25] [26] [27]. To our knowledge, few studies focused on hole-buffering application for optoelectronic devices [15]. The fluorescence intensity of aromatic materials substituted with azomethine moieties is very weak due to quenching by photo-induced electron transfer (PET) [28] [29]. This characteristic is beneficiary for hole-buffering application in PLEDs, since its presence will not deteriorate color purity of the emission.

In this study, we synthesized a new azomethine-based molecule TAZS (aromatic 1,2,4-triazolyl as core) containing three peripheral trihydroxy tert-butyl groups. The bulky, polar trihydroxy tert-butyl groups not only increase solubility but also prevent aggregate formation during casting by wet processes. ${ }^{1} \mathrm{H} \mathrm{NMR}$, 2D COSY NMR, FT-IR, and mass spectrometry were used to characterize structure of TAZS. Multilayer PLEDs (ITO/PEDOT: PSS/TAZS/SY/ETL/LiF/Al) have been successfully fabricated by subsequent spin-coating of hole-injecting PEDOT: PSS layer, hole-buffer TAZS layer, and emissive SY layer. Insertion of TAZS as hole-buffer layer (HBL) effectively enhanced maximum luminance and maximum current efficiency to $19,046 \mathrm{~cd} / \mathrm{m}^{2}$ and $4.08 \mathrm{~cd} / \mathrm{A}$, respectively, from those without the HBL $\left(8484 \mathrm{~cd} / \mathrm{m}^{2}, 2.13 \mathrm{~cd} / \mathrm{A}\right)$. 


\section{Experimental}

\subsection{Synthesis of TAZS}

All the reagents and materials were from commercial sources and used without further purification. Anhydrous tetrahydrofuran was obtained by refluxing with sodium under $\mathrm{N}_{2}$ atmosphere overnight. Scheme 1 depicts the detailed synthetic routes of TAZS from 4-bromobenzoyl chloride (1).

A mixture of 4-bromobenzoyl chloride $(1: 3.29 \mathrm{~g}, 15.0 \mathrm{mmol})$ in $n$-methylpyrrolidone $(30 \mathrm{~mL})$ was added hydrazine monohydrate $(0.38 \mathrm{~g}, 7.5 \mathrm{mmol})$ under continuous stirring. The mixture was stirred at room temperature under $\mathrm{N}_{2}$ atmosphere for 1 day. The mixture was poured into a large amount of water (200 $\mathrm{mL}$ ), the appearing precipitate was collected by filtration, and then washed completely with ethyl acetate. The final product was dried under vacuum oven at $70{ }^{\circ} \mathrm{C}$ to obtain 2 (yield: $\left.4.61 \mathrm{~g}, 77.2 \%\right) .{ }^{1} \mathrm{H}$ NMR (600 MHz, DMSO-d ${ }_{6}, \mathrm{ppm}$ ): $\delta$ 10.62 (s, 2H, -NH-), $7.85-7.84$ (d, J = 8.6 Hz, 4H, Ar-H), $7.75-7.74$ (d, J = 8.2 $\mathrm{Hz}, 4 \mathrm{H}, \mathrm{Ar}-\mathrm{H})$.

A mixture of $2(1.60 \mathrm{~g}, 4.0 \mathrm{mmol})$, phosphorus pentachloride $(1.92 \mathrm{~g}, 9.3$ mmol) and toluene $(30 \mathrm{~mL})$ was stirred at $120^{\circ} \mathrm{C}$ for $3.5 \mathrm{hrs}$. After removal of toluene by a rotary evaporator, the crude product was washed with water, followed with drying in vacuum oven at $80^{\circ} \mathrm{C}$. The crude was recrystallized from ethanol and chloroform to obtain 3 (yield: $0.81 \mathrm{~g}, 46.3 \%) .{ }^{1} \mathrm{H}$ NMR $(600 \mathrm{MHz}$, $\left.\mathrm{CDCl}_{3}, \mathrm{ppm}\right): \delta 8.00-7.98(\mathrm{~d}, \mathrm{~J}=8.2 \mathrm{~Hz}, 4 \mathrm{H}, \mathrm{Ar}-\mathrm{H}), 7.62-7.60(\mathrm{~d}, \mathrm{~J}=8.2 \mathrm{~Hz}$, $4 \mathrm{H}, \mathrm{Ar}-\mathrm{H})$.

A mixture of 3 (0.86 g, $2.0 \mathrm{mmol}), p$-bromoaniline $(0.34 \mathrm{~g}, 2.0 \mathrm{mmol})$ and $\mathrm{N}, \mathrm{N}$-dimethylaniline $(15 \mathrm{~mL})$ was stirred at $135^{\circ} \mathrm{C}$ for $12 \mathrm{hrs}$. The reaction mixture was poured into $2 \mathrm{~N} \mathrm{HCl}_{(\mathrm{aq})}(30 \mathrm{~mL})$ and the appearing solids were collected by filtration, washed with water and dried in vacuum oven at $80^{\circ} \mathrm{C}$. Then residues were recrystallized from $\mathrm{H}_{2} \mathrm{O}$ and dimethyl sulfoxide (DMSO) to provide


Scheme 1. Synthetic routes of TAZS. 
4 (yield: $0.77 \mathrm{~g}, 72.0 \%) .{ }^{1} \mathrm{H}$ NMR (600 MHz, DMSO-d 6 , ppm): $\delta 7.69-7.67$ (d, J $=8.1 \mathrm{~Hz}, 2 \mathrm{H}, \mathrm{Ar}-\mathrm{H}), 7.62-7.60(\mathrm{~d}, \mathrm{~J}=8.1 \mathrm{~Hz}, 4 \mathrm{H}, \mathrm{Ar}-\mathrm{H}), 7.40-7.38(\mathrm{~d}, \mathrm{~J}=8.0$ $\mathrm{Hz}, 2 \mathrm{H}, \mathrm{Ar}-\mathrm{H}), 7.32-7.30$ (d, J = 8.0 Hz, 4H, Ar-H).

To a two-necked flask were added with 5-bromo-2-hydroxybenzaldehyde ( $1.50 \mathrm{~g}, 7.5 \mathrm{mmol})$, potassium acetate $(1.86 \mathrm{~g}, 18.9 \mathrm{mmol})$ and bis(pinacolato) diboron $(2.31 \mathrm{~g}, 9.1 \mathrm{mmol})$. After adding $\left[\mathrm{Pd}(\mathrm{dppf}) \mathrm{Cl}_{2}\right](0.36 \mathrm{~g}, 0.5 \mathrm{mmol})$ and THF $(30 \mathrm{~mL})$, the mixture was stirred at $70^{\circ} \mathrm{C}$ for $18 \mathrm{hrs}$. After removing the solvent by a rotary evaporator, the residue was re-dissolved in dichloromethane, followed by extracting with water. The combined organic layer was concentrated by a rotary evaporator, then further purified by column chromatography using ethyl acetate and $n$-hexane $(\mathrm{v} / \mathrm{v}=1: 12)$ as an eluent to obtain 5 (yield: $1.04 \mathrm{~g}$, 56.1\%). ${ }^{1} \mathrm{H}$ NMR (600 MHz, $\left.\mathrm{CDCl}_{3}, \mathrm{ppm}\right): \delta 11.22(\mathrm{~s}, 1 \mathrm{H},-\mathrm{OH}), 9.92(\mathrm{~s}, 1 \mathrm{H}$, $-\mathrm{CH}=\mathrm{O}), 8.04(\mathrm{~d}, 1 \mathrm{H}, \mathrm{Ar}-\mathrm{H}), 7.94(\mathrm{dd}, 1 \mathrm{H}, \mathrm{J}=8.2 \mathrm{~Hz}, \mathrm{Ar}-\mathrm{H}), 6.98(\mathrm{~d}, 1 \mathrm{H}, \mathrm{J}=$ $8.3 \mathrm{~Hz}, \mathrm{Ar}-\mathrm{H}), 1.35$ (s, 12H, $-\mathrm{CH}_{3}$ ).

To a two-necked flask were added with 4 (0.32 g, $0.6 \mathrm{mmol}), 5$ (0.60 g, 2.4 $\mathrm{mmol})$ and $\left[(t-\mathrm{Bu})_{3} \mathrm{PH}\right] \mathrm{BF}_{4}(88.0 \mathrm{mg}, 0.3 \mathrm{mmol})$. Then $\mathrm{Pd}\left(\mathrm{PPh}_{3}\right)_{4}(34.7 \mathrm{mg}, 0.03$ $\mathrm{mmol})$, THF $(20 \mathrm{~mL})$ and $\mathrm{K}_{2} \mathrm{CO}_{3(\mathrm{aq})}(2 \mathrm{M}, 3 \mathrm{~mL})$ were added under nitrogen atmosphere. The mixture was stirred at $70^{\circ} \mathrm{C}$ for $24 \mathrm{hrs}$. It was poured into a large amount of water and then extracted with chloroform. The combined organic layer was collected and the solvent was removed using a rotary evaporator. The crude product was further purified by a column chromatograph using ethyl acetate and $n$-hexane $(\mathrm{v} / \mathrm{v}=2: 1)$ as an eluent to obtain 6 (yield: $0.18 \mathrm{~g}, 46.4 \%) .{ }^{1} \mathrm{H}$ NMR (600 MHz, DMSO-d $\left.{ }_{6}, \mathrm{ppm}\right): \delta 10.94$ (s, 1H, -OH), 10.89 (s, 2H, -OH), $10.30(\mathrm{~s}, 1 \mathrm{H},-\mathrm{CH}=\mathrm{O}), 10.28$ (s, 2H, $-\mathrm{CH}=\mathrm{O}), 8.01$ (s, 1H, Ar-H), $7.95-7.93$ (m, $3 \mathrm{H}, \mathrm{Ar}-\mathrm{H}), 7.88-7.87(\mathrm{~d}, \mathrm{~J}=7.9 \mathrm{~Hz}, 2 \mathrm{H}, \mathrm{Ar}-\mathrm{H}), 7.82-7.81(\mathrm{~d}, \mathrm{~J}=8.5 \mathrm{~Hz}, 2 \mathrm{H}$, Ar-H), $7.68-7.66$ (d, J = 7.9 Hz, 4H, Ar-H), $7.58-7.56$ (d, J = 8.5 Hz, 2H, Ar-H), $7.52-7.51$ (d, J = 8.0 Hz, 4H, Ar-H), $7.11-7.09$ (d, J = 8.5 Hz, 1H, Ar-H), $7.07-7.06$ (d, J = 8.5 Hz, 2H, Ar-H).

A mixture of 6 (0.5 mmol, $0.33 \mathrm{~g}), 2$-amino-2-(hydroxymethyl)-1,3-propanediol (tris, 7: $2.05 \mathrm{mmol}, 0.25 \mathrm{~g}$ ) and methanol $(50 \mathrm{~mL})$ was stirred at $55^{\circ} \mathrm{C}$ for $24 \mathrm{hrs}$. After removing methanol bya rotary evaporator, the resulted residue was washed successively with acetone and chloroform to obtain TAZS (yield: $0.44 \mathrm{~g}$, 90.8\%). ${ }^{1} \mathrm{H}$ NMR (600 MHz, DMSO-d, ppm): $\delta 14.73$ (s, 1H), 14.69 (s, 2H), 8.62 (s, 1H, -NH-), 8.60 (s, 2H, -NH-), 7.87 (s, 1H, Ar-H), $7.82-7.80$ (m, 4H, Ar-H), $7.72-7.71(\mathrm{~d}, \mathrm{~J}=8.4 \mathrm{~Hz}, 1 \mathrm{H}, \mathrm{Ar}-\mathrm{H}), 7.67-7.66(\mathrm{~m}, 6 \mathrm{H}, \mathrm{Ar}-\mathrm{H}), 7.53-7.52$ (d, J $=7.9 \mathrm{~Hz}, 2 \mathrm{H}, \mathrm{Ar}-\mathrm{H}), 7.49-7.48(\mathrm{~d}, \mathrm{~J}=7.9 \mathrm{~Hz}, 4 \mathrm{H}, \mathrm{Ar}-\mathrm{H}), 6.83-6.81(\mathrm{~d}, \mathrm{~J}=8.7$ $\mathrm{Hz}, 1 \mathrm{H}, \mathrm{Ar}-\mathrm{H}), 6.79-6.78(\mathrm{~d}, \mathrm{~J}=8.8 \mathrm{~Hz}, 2 \mathrm{H}, \mathrm{Ar}-\mathrm{H}), 4.80(\mathrm{~m}, 9 \mathrm{H},-\mathrm{OH}), 3.61$ (m, $\left.18 \mathrm{H},-\mathrm{CH}_{2}^{-}\right)$.

\subsection{General Procedures}

The ${ }^{1} \mathrm{H}$ NMR and COSY NMR spectra were measured using a Bruker AV-600 $\mathrm{MHz}$ spectrometer, with the chemical shifts reported in ppm and using tetramethylsilane as the internal standard. The FT-IR spectra of compounds (in pellet form) were recorded with a Jasco FT-IR Spectrometer Volar III. Mass spectra 
were measured with a mass spectrometer (Bruker Autoflex III TOF/TOF). Thermogravimetric analysis (TGA) of TAZS employed a PerkinElmer TGA-7 from $50^{\circ} \mathrm{C}$ to $800^{\circ} \mathrm{C}$ at a heating rate of $10^{\circ} \mathrm{C} / \mathrm{min}$, under a nitrogen flow rate of $20 \mathrm{~mL} / \mathrm{min}$. The thermal decomposition temperature $\left(\mathrm{T}_{\mathrm{d}}\right)$ is the temperature at $5 \%$ weight loss of the sample. Differential scanning calorimetric (DSC) measurements were conducted under nitrogen atmosphere, using a Mettler Toledo DSC 1 Star System, at heating rate of $10^{\circ} \mathrm{C} / \mathrm{min}$. UV/Vis absorption spectra and photoluminescence (PL) spectra were recorded on a Jasco V-550 spectrophotometer and a Hitachi F-4500 fluorescence spectrophotometer, respectively. Cyclic voltammetry $(\mathrm{CV})$ were carried out on a voltammetric apparatus (Model $\mathrm{CV}-50 \mathrm{~W}$ ) equipped with a three-electrode cell at a scan rate of $100 \mathrm{mV} / \mathrm{s}$. The cell was composed of a carbon as the working electrode, $\mathrm{Ag} / \mathrm{AgNO}_{3}$ electrode as the reference electrode and a platinum wire as the auxiliary electrode. The electrodes were immersed in acetonitrile containing $0.1 \mathrm{M}(n-\mathrm{Bu})_{4} \mathrm{NClO}_{4}$ as electrolyte. The energy levels were estimated using the ferrocene (FOC) value of -4.8 $\mathrm{eV}$ with respect to vacuum level, which is defined as zero. The onset potentials of oxidation and reduction were determined by the intersection of two tangent lines drawn at the background and rising current. Film thickness was measured with a surface profiler, alpha-step 500. Surface morphology of spin-coated films was measured with an atomic force microscope (AFM), equipped with a Veeco/Digital Instrument Scanning Probe Microscope (tapping mode) and a Nanoscope III controller.

\subsection{Device Fabrication and Characterization}

Indium tin oxide (ITO)-patterned glass substrate was consecutively cleaned using neutral detergent, deionized water, acetone and isopropyl alcohol, immersing in an ultrasonic bath at $50^{\circ} \mathrm{C}$, each for $20 \mathrm{~min}$. In addition, the ITO substrate was rinsed with deionized water after each step. The cleaned ITO substrates were baked at $120^{\circ} \mathrm{C}$ for $20 \mathrm{~min}$ to remove the deionized water. Finally, the cleaned ITOs were treated in an UV-ozone chamber for $20 \mathrm{~min}$. A solution of PEDOT: PSS was spin-coated onto the ITO substrate at a spin rate of $3000 \mathrm{rpm}$ and annealed at $150^{\circ} \mathrm{C}$ for $20 \mathrm{~min}$ as a hole injection layer. A solution of TAZS in ethanol and DMF ( $/ \mathrm{v}=5 / 1)$ was spin-coated onto the PEDOT: PSS layer and annealed at $110^{\circ} \mathrm{C}$ for $20 \mathrm{~min}$ to form as the hole-buffer layer (HBL). The concentration was $1.5 \mathrm{mg} / \mathrm{mL}$, with the spin rate varying from $1000 \mathrm{rpm}$ to 4000 rpm to obtain different film thickness. Then, the fluorescent poly ( $p a-$ ra-phenylene vinylene) derivative (Super Yellow PPV, SY, from Merck) was spin-coated at $4000 \mathrm{rpm}$ on top of the TAZS layer and annealed at $70^{\circ} \mathrm{C}$ for 20 min to construct the emission layer (EML). Finally, $\mathrm{LiF}(1 \mathrm{~nm})$ and $\mathrm{Al}(90 \mathrm{~nm})$ was subsequently vacuum deposited on top of the EML as the cathode. The luminance-voltage, current density-voltage relationships and electroluminescence spectra (EL) of the multilayer PLEDs were recorded using a combination of the Keithley source-meter (model 2400) and an Ocean Optics usb2000 fluorescence spectrophotometer. The thickness of deposited films was measured using a sur- 
face profiler, alpha-step 500 .

\section{Results and Discussion}

\subsection{Synthesis and Characterization}

Scheme 1 depicts the detailed synthetic procedures of TAZS from 4-bromobenzoyl chloride (1) within five steps. The ${ }^{1} \mathrm{H}$ NMR spectra of intermediates $(2,3,4,5)$ are attached as Figures S1-S4 in Supplementary Information. Chemical structures of $\mathbf{2}$ - $\mathbf{5}$ were satisfactorily confirmed by the ${ }^{1} \mathrm{H}$ NMR in which the protons were easily assigned. Compound 6 with three benzaldehyde peripherals was synthesized from 3,4,5-tri(4-bromophenyl)-4H-1,2,4-triazole (4) and 2-hydroxy5-(4,4,5,5-tetramethyl-1,3,2-dioxaborolan-2-yl) benzaldehyde (5) by the Suzuki coupling reaction. The ${ }^{1} \mathrm{H}$ NMR and 2D COSY spectra of 6 are also provided as Figure S5 and Figure S6. All protons were successfully assigned using the 2D COSY spectra (Figure S6) and its structure was satisfactorily confirmed based on the integral areas of the protons (Figure S5). Finally, the target TAZS with three azomethine linkages was synthesized by the Schiff base-forming condensation of 6 and 2-amino-2-(hydroxymethyl)-1,3-propanediol(7: tris). The purpose of attaching high polar trihydroxy tert-butyl groups is to improve the solubility of TAZS in protic solvents such as alcohol. Figure 1 shows the ${ }^{1} \mathrm{H}$ NMR spectrum of TAZS, with all the proton peaks assigned by the 2D COSY NMR spectrum (Figure S7). The FTIR spectrum confirmed successful formation of azomethine linkages by the presence of $\mathrm{C}=\mathrm{N}$ vibrational absorption peak at 1633 $\mathrm{cm}^{-1}$ and a broad band of hydroxyl groups at $3310 \mathrm{~cm}^{-1}$ (Figure S8). The MALDI/TOF-MS spectra of 6 and TAZS are demonstrated in Figure S9 and Figure S10 and Figure S11 and Figure S12, respectively. The largest molecular masses $(\mathrm{m} / \mathrm{z})$ of 6 and TAZS were 658.02 (Figure S9) and 967.23 (Figure S11), respectively, which are very close to true molecular weights $(657.67,967.03)$.

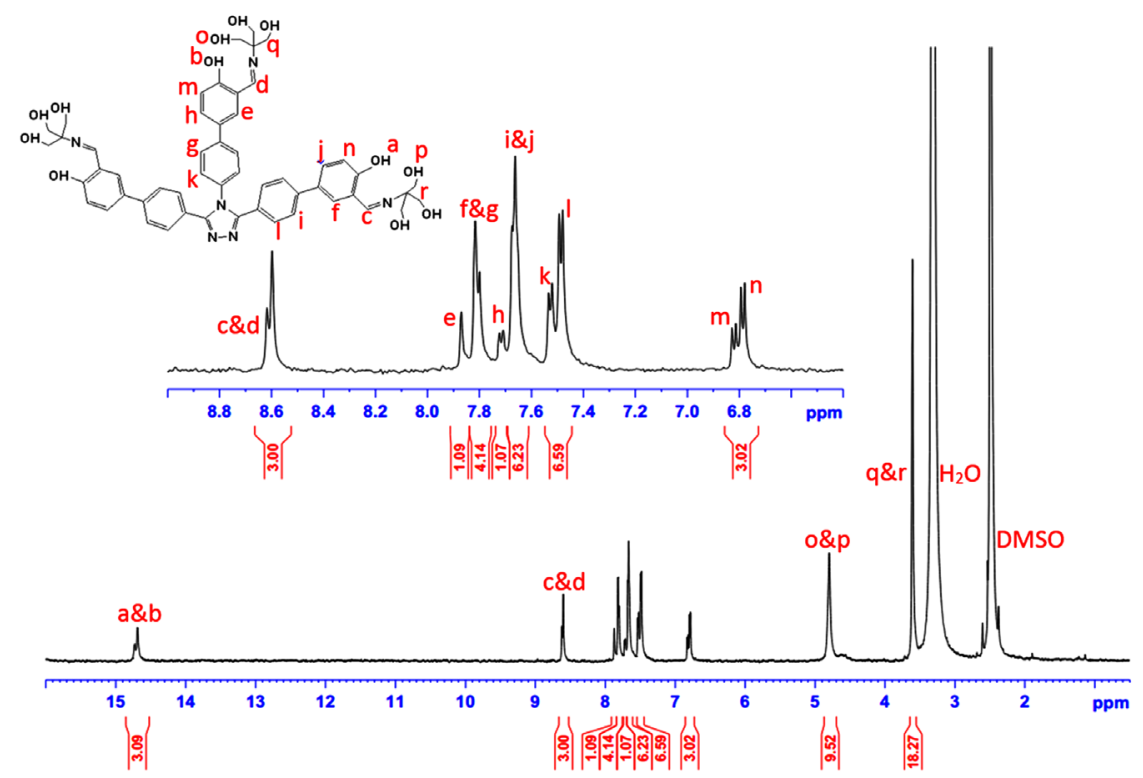

Figure 1. ${ }^{1} \mathrm{H}$ NMR spectrum of TAZS in DMSO- $\mathrm{d}_{6}$. 


\subsection{Thermal and Optical Properties of TAZS}

Thermal decomposition and transition properties of TAZS were investigated using a thermogravimetric analytical apparatus (TGA) and a differential scanning calorimeter (DSC), respectively, at a scanning rate of $10^{\circ} \mathrm{C} / \mathrm{min}$ and under a nitrogen atmosphere. TAZS reveals a two-step thermal decomposition (Figure $\mathrm{S} 13(\mathrm{a})$ ) and the thermal decomposition temperature $\left(\mathrm{T}_{\mathrm{d}}\right)$ is $264^{\circ} \mathrm{C}$ (at $5 \%$ weight loss). The first-step decomposition of TAZS is attributable to the thermal degradation of peripheral trihydroxy tert-butyl groups. The second stage would be the decomposition of aromatic chromophores. Furthermore, the residue at $800^{\circ} \mathrm{C}$ was still high at ca. $43 \%$, which is probably owing to thermal carbonization of rigid aromatic core including triazolyl group. However, TAZS does not exhibit any thermal transitions up to $200^{\circ} \mathrm{C}$, as shown in Figure S13(b), suggesting that it is amorphous material in film state. The bulky trihydroxy tert-butyl terminals and high twist angle between triazolyl core and phenyl groups prevent the crystallization process during film casting. Amorphous material is highly required for PLEDs because it effectively reduces performance degradation caused by crystallization during device operation.

Figure 2 shows the normalized UV/Visible absorption and photoluminescence (PL) spectra of TAZS in ethanol solution and in film state, with the characteristic data summarized in Table 1 . In ethanol, the main absorption maximum of TAZS is peaked at $315 \mathrm{~nm}$, with a smaller peak located at $421 \mathrm{~nm}$. The

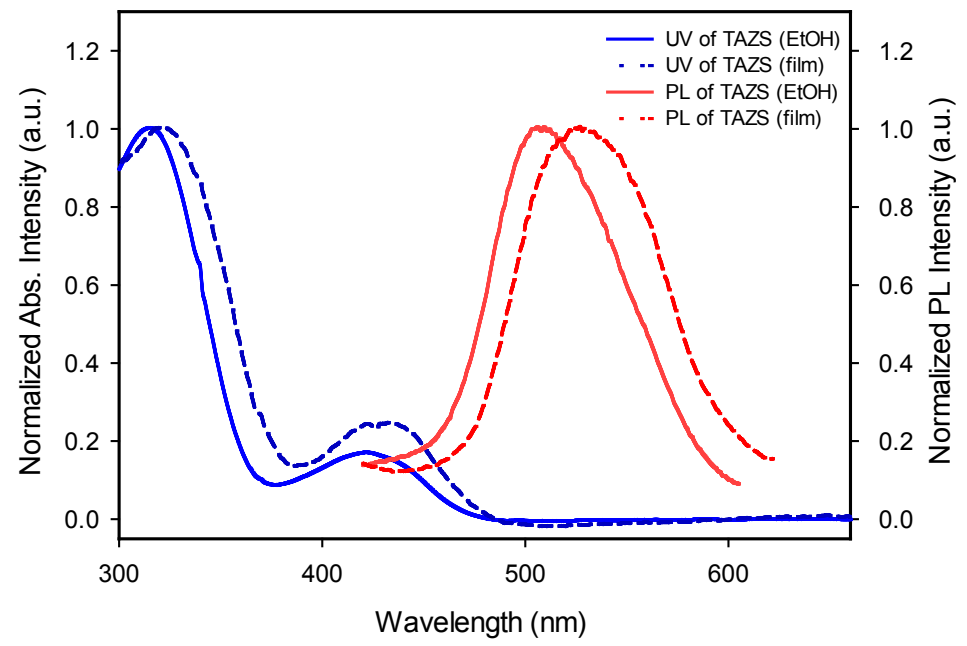

Figure 2. Normalized absorption spectra and photoluminescence spectra of TAZS in ethanol solution (-) and in the film state (---).

Table 1. Optical properties of TAZS.

\begin{tabular}{cccccc}
\hline & \multicolumn{2}{c}{ UV/Vis $\lambda_{\max }(\mathrm{nm})$} & \multicolumn{2}{c}{ PL $\lambda_{\max }(\mathrm{nm})$} & \multirow{2}{*}{$\begin{array}{c}\mathrm{E}_{\mathrm{g}}{ }^{\mathrm{ppt}} \\
\end{array}$} \\
\cline { 2 - 5 } & Solution $^{\mathrm{a}}$ & Film $^{\mathrm{b}}$ & Solution $^{\mathrm{a}}$ & Film $^{\mathrm{b}}$ & $(\mathrm{eV})^{\mathrm{c}}$ \\
\hline TAZS & 315,421 & 321,433 & 509 & 527 & 3.24 \\
\hline
\end{tabular}

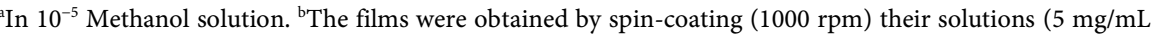




main absorption of TAZS is attributed to the $\pi-\pi^{*}$ transitions of conjugated moieties, whereas the absorption band at $421 \mathrm{~nm}$ is attributable to the $\mathrm{n}-\pi^{\star}$ transitions of conjugated region including terminal azomethines. The PL intensity of TAZS is extremely low in both solution and film state (the PL spectra in Figure 2 is after normalization). This is because of significant fluorescence quenching due to the photo-induced electron transfer (PET) from azomehtine groups [28] [29]. Non-emissive HBL is beneficial to high color purity, because even slight emission from HBL may deteriorate emission color. The PL spectra of TAZS in the ethanol and solid state are located at $509 \mathrm{~nm}$ and $527 \mathrm{~nm}$, respectively. The absorption and PL maxima of TAZS in solid state are red-shifted slightly relative to those in ethanol solution. The redshift is probably owing to molecular aggregation caused by stronger intermolecular interactions.

\subsection{Electrochemical Properties}

Cyclic voltammetric apparatus has been constantly employed to measure the electrochemical properties, especially onset oxidation and reduction potentials, of organic and polymeric materials. The highest occupied molecular orbital (HOMO) and lowest unoccupied molecular orbital (LUMO) energy levels are readily estimated from the onset oxidation and reduction potentials, respectively. Figure 3 demonstrates the cyclic voltammogram (CV) of TAZS and Table 2 summaries corresponding electrochemical data. The CV curve was not a closed loop, probably attributed to the equilibrium between TAZS and electrolyte ion

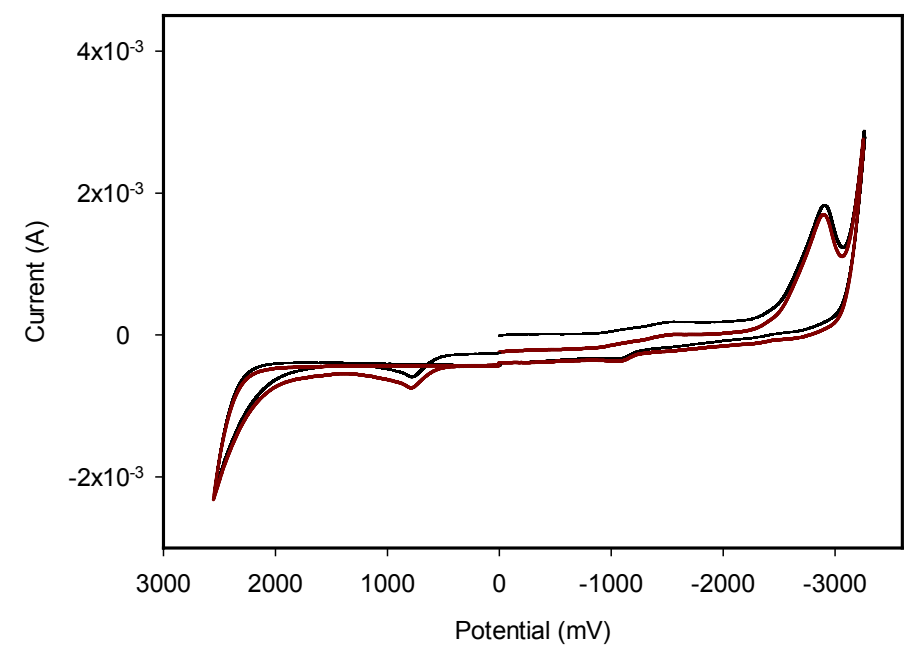

Figure 3. Cyclic voltammogram of TAZS in $0.1 \mathrm{M}(n-\mathrm{Bu})_{4} \mathrm{NClO}_{4}$; scan rate: $100 \mathrm{mV} / \mathrm{s}$.

Table 2. Electrochemical properties of TAZS.

\begin{tabular}{|c|c|c|c|c|c|c|}
\hline & $\begin{array}{c}\mathrm{E}_{\text {onset(ox) vs. FOC }} \\
(\mathrm{V})^{\mathrm{a}}\end{array}$ & $\begin{array}{c}\mathrm{E}_{\text {onset(red) vs. FOC }} \\
(\mathrm{V})^{\mathrm{a}}\end{array}$ & $\begin{array}{l}\mathrm{E}_{\text {Hомо }} \\
(\mathrm{eV})^{\mathrm{b}}\end{array}$ & $\begin{array}{l}\mathrm{E}_{\mathrm{LUMO}} \\
(\mathrm{eV})^{\mathrm{c}}\end{array}$ & $\begin{array}{c}\mathrm{E}_{\mathrm{g}}^{\mathrm{el}} \\
(\mathrm{eV})^{\mathrm{d}}\end{array}$ & $\begin{array}{l}\mathrm{E}_{\mathrm{g}}{ }^{\text {ppt }} \\
(\mathrm{eV})^{\mathrm{e}}\end{array}$ \\
\hline TAZS & 0.43 & -2.40 & -5.23 & -2.40 & 2.83 & 3.24 \\
\hline
\end{tabular}


was still not established. The estimated HOMO and LUMO levels of TAZS are $-5.23 \mathrm{eV}$ and $-2.40 \mathrm{eV}$, respectively, leading to a bandgap of $2.83 \mathrm{eV}$. This bandgap is much lower than the optically estimated one $\left(\mathrm{E}_{\mathrm{g}}{ }^{\mathrm{opt}}=3.24 \mathrm{eV}\right)$, due probably to the bipolar characteristic of TAZS. The oxidation starts from electron-rich azomethine moiety, while the reduction begins from electron-withdrawing triazolyl core. Accordingly, the electrochemically estimated bandgap $\left(\mathrm{E}_{\mathrm{g}}{ }^{\mathrm{el}}\right)$ is much lower than that calculated from onset absorption $\left(\mathrm{E}_{\mathrm{g}}{ }^{\text {opt }}\right)$. Figure 4 demonstrates the energy band diagrams of composition layers in multilayer PLEDs (ITO/PEDOT: PSS/TAZS/SY/LiF/Al). The HOMO level of TAZS ( -5.23 $\mathrm{eV})$ is deeper than $-5.0 \mathrm{eV}$ of PEDOT: PSS; thus there is a barrier height $\left(\Delta \mathrm{E}_{\mathrm{h}}=\right.$ $0.23 \mathrm{eV}$ ) at the interface of TAZS and hole-injecting PEDOT: PSS layers. Accordingly, the presence of TAZS layer will reduce injection/transport rate of holes. In addition, the LUMO level $(-2.40 \mathrm{eV})$ of TAZS is higher than $-2.8 \mathrm{eV}$ of SY emissive layer to result in a barrier height in the interface. Moreover, electron-withdrawing triazolyl core tends to obstruct holes' transport. Therefore, TAZS is expected to be an effective hole-buffer layer in PLEDs to raise charges' recombination ratio that results in enhanced emission efficiency.

\subsection{Morphological Properties}

Film homogeneity of compositional layers, whether in OLEDs or PLEDs, is an essential prerequisite to obtain efficient and reproducible devices. When use wet processes such as spin coating or inkjet printing to deposit film, polymers usually give rise to more homogeneous film than low molecular weight compounds. This is because of intrinsic film-forming property of polymers attributable to high molecular weight. On the contrary, the film-forming property of low molecular compounds is usually poor by solution processes. However, as illustrated in Figure 5, the surface morphologies of TAZS obtained from atomic force microscopy (AFM) were quite smooth. The root-mean-square (rms) surface roughness were between 1.90 to $3.33 \mathrm{~nm}$ (Table 3), compared with $1.20 \mathrm{~nm}$ of

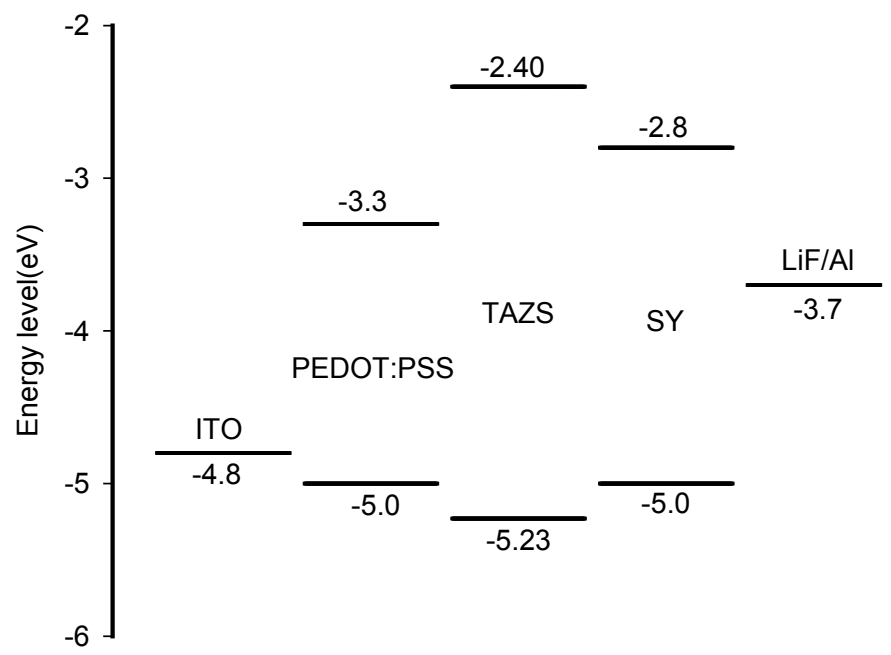

Figure 4. Energy band diagrams of PLEDs (ITO/PEDOT: PSS/TAZS/SY/LiF/Al). 


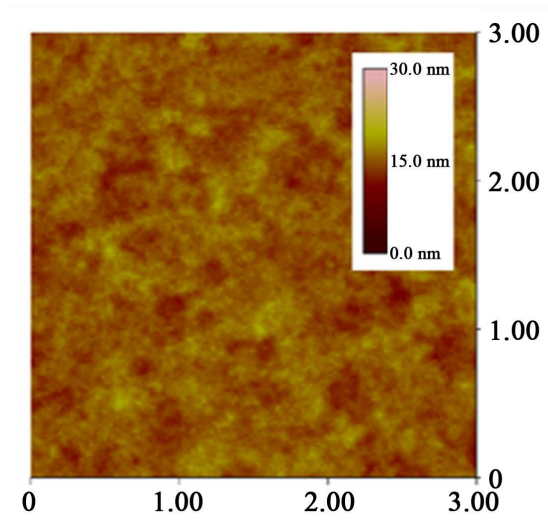

(a)

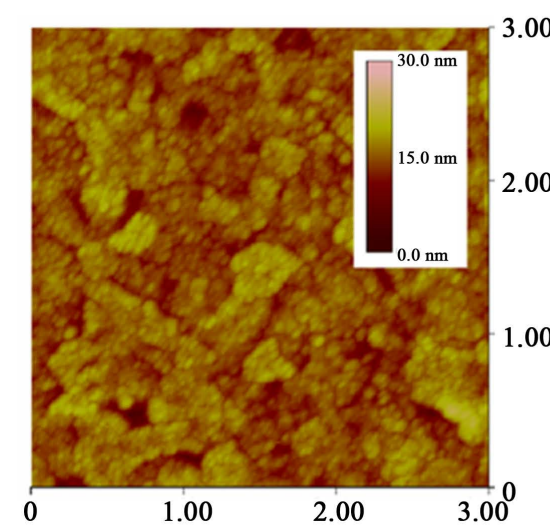

(d)

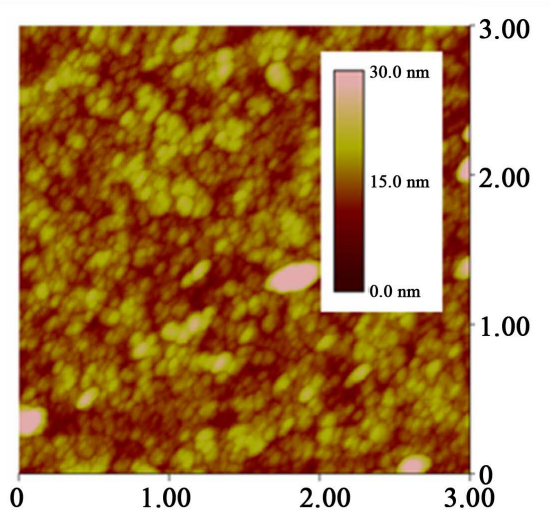

(b)

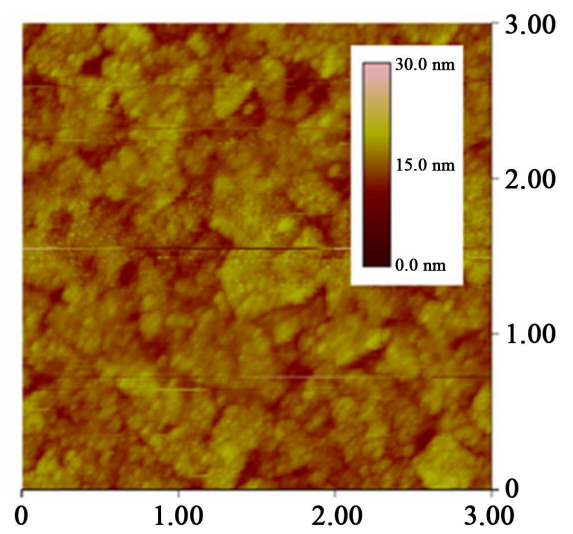

(e)

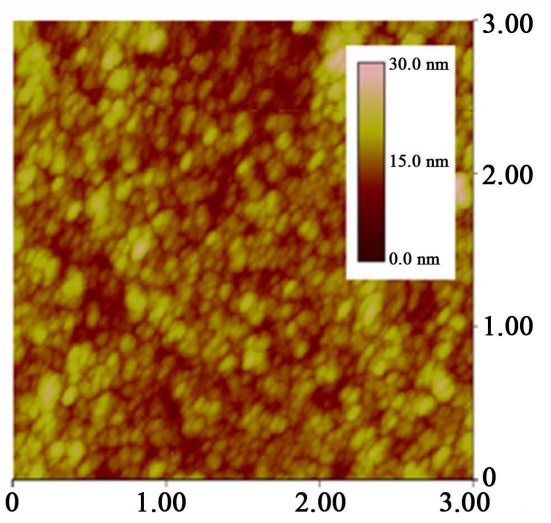

(c)

Figure 5. AFM images of (a) PEDOT: PSS and (b)-(e) TAZS on the top of PEDOT: PSS film deposited at different spin rate. Spin rate: (b) 1000; (c) 2000; (d) 3000; (e) $4000 \mathrm{rpm}$.

Table 3. Thickness and roughness of films deposited at different spin rates ${ }^{\mathrm{a}}$.

\begin{tabular}{cccc}
\hline Deposited films & Spin rate $(\mathrm{rpm})$ & Thickness $(\mathrm{nm})$ & ${\text { Roughness }(\mathrm{nm})^{\mathrm{b}}}^{\mathrm{b}}$ \\
\hline PEDOT: PSS & 3000 & 40 & 1.20 \\
& 1000 & 34 & 3.33 \\
TAZS $^{\mathrm{a}}$ & 2000 & 28 & 2.75 \\
& 3000 & 16 & 2.00 \\
& 4000 & 5 & 1.90 \\
\hline
\end{tabular}

${ }^{a}$ Films were obtained by spin-coating of TAZS solution in EtOH and DMF $(\mathrm{v} / \mathrm{v}=5 / 1)$; the concentration was $1.5 \mathrm{mg} / \mathrm{mL}$. ${ }^{b}$ Root-mean-square (rms) surface roughness.

the underlying PEDDOT: PSS layer. Moreover, the roughness decreased from $3.33 \mathrm{~nm}$ to $1.90 \mathrm{~nm}$ with spin rate increasing from $1000 \mathrm{rpm}$ to $4000 \mathrm{rpm}$. The bulky trihydroxy tert-butyl groups on the periphery of TAZS are effective to prevent extreme aggregation in film state. This is coincident with previous result obtained in DSC investigation, which confirmed the amorphous phase of TAZS in solid state. Amorphous materials usually lead to better homogeneous morphology when deposited by solution processes. 


\subsection{Single-Carrier Transporting Property}

In order to evaluate charge-transporting properties of multilayer PLEDs in the presence of TAZS layer, we fabricated single-carrier (hole-only and electron-only) devices by appropriate selection of cathode and anode metals, respectively. The hole-only device (HOD), ITO/PEDOT: PSS/TAZS/SY/LiF/Au, used high work function $\mathrm{Au}(-5.1 \mathrm{eV})$ as the cathode instead of aluminum $(\mathrm{Al})$. High work-function $\mathrm{Au}$ cathode restricts electron injection; therefore, holes contribute exclusively to current density. The electron-only device (EOD), Glass/PEDOT: PSS/Ag/TAZS/SY/LiF/Al, employed silver $(\mathrm{Ag})$ as the anode to prevent hole injection into EML [30] [31]. The function of PEDOT: PSS layer was to smooth the surface of ITO glass. Figure 6 depicts current density versus



(a)

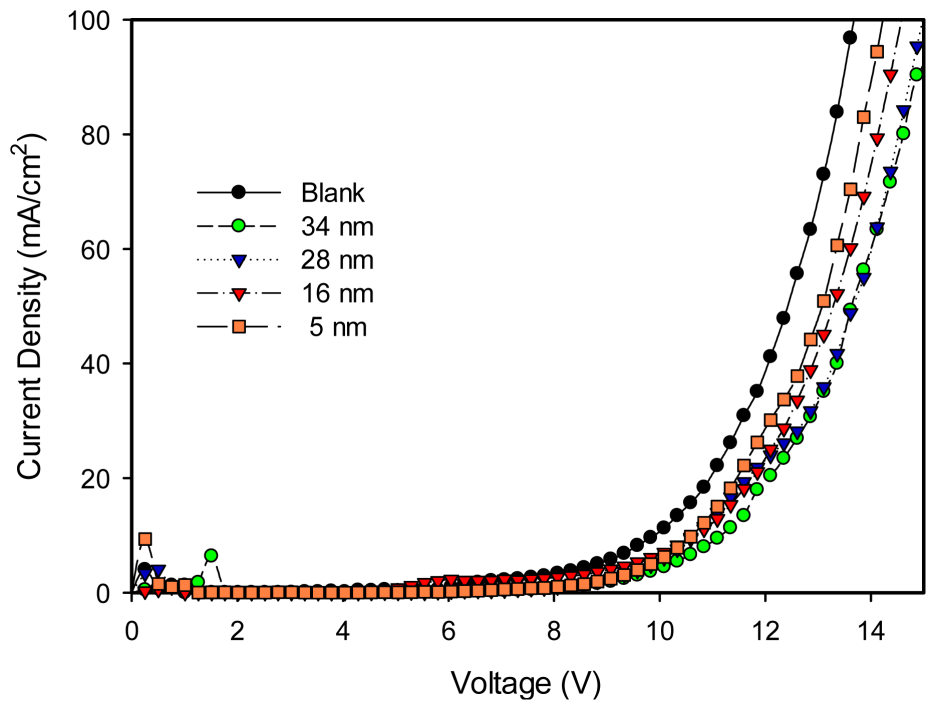

(b)

Figure 6. (a) Current density versus voltage characteristics for HOD with and without TAZS layer; (b) Current density versus voltage characteristics for EOD with and without TAZS layer. 
voltage of the single carrier devices. For blank devices without TAZS layer, the current density of HOD is much higher than that of EOD under the same operating voltage. For instance, at $6.0 \mathrm{~V}$ the current density was ca. $75 \mathrm{~mA} / \mathrm{cm}^{2}$ for HOD; however, it was almost non-detectable for EOD. Apparently, holes transport much faster than electrons in these PLEDs, leading to low charge recombination ratio and degraded emission efficiency. Therefore, reduction of holes' transport is necessary to raise charge recombination ratio and emission efficiency.

For hole-only devices, current density decreases dramatically after the insertion of TAZS layer (Figure 6(a)), confirming its hole-buffering capability. Moreover, the reduction in current density increases greatly with thickness from $5 \mathrm{~nm}$ to $34 \mathrm{~nm}$. On the other hand, for electron-only devices the current density decreases only slightly in the presence of TAZS layer (Figure 6(b)). From the results of single-carrier devices, it is clear that the TAZS layer reveals mainly hole-buffering capability to raise charges' recombination ratio and emission efficiency.

\subsection{Electroluminescent Properties}

To determine the applicability of TAZS as hole-buffer layer (HBL), multilayer PLEDs were fabricated with a device structure of ITO/PEDOT: PSS/TAZS/SY/ LiF/Al. The PEDOT: PSS is conventional hole-injection layer, while the Super Yellow (SY) was employed as the fluorescent emitter. The hole-buffering TAZS layer was deposited between hole-injection PEDOT: PSS and emissive SY layers. All of the organic layers, including PEDOT: PSS, TAZS and SY, were deposited by spin-coating process. The thickness of TAZS layer varied from $5 \mathrm{~nm}$ to 34 $\mathrm{nm}$, depending on the spin rates (Table 3). Figure 4 demonstrates the energy level diagram of composition layers in the PLEDs. The TAZS $(-5.23 \mathrm{eV})$ has a HOMO level deeper than SY $(-5.0 \mathrm{eV})$, with a barrier height of $0.23 \mathrm{eV}$ for holes. In addition, as mentioned above, the electron-withdrawing aromatic 1,2,4-triazolyl moieties reduce transport of holes. This indicates that TAZS acts mainly as hole-buffering layer.

Figure 7 presents the luminance-voltage, current density-voltage characteristics, and current efficiency versus current density of the multilayer PLEDS, with the corresponding data summarized in Table. Insertion of TAZS layer leads to obvious reduction in current density and increase in turn-on voltage (Figure 7(b), Table 4). This is attributable to the hole-buffering effect of the TAZS layer. However, the maximum luminance, maximum current efficiency, and maximum luminous power efficiency reveal significant enhancement except for the device with $34 \mathrm{~nm}$ of TAZS layer. For instance, at $16 \mathrm{~nm}$ TAZS layer the luminance and current efficiency are optimal at $19,046 \mathrm{~cd} / \mathrm{m}^{2}$ and $4.08 \mathrm{~cd} / \mathrm{A}$, respectively. The device performance is superior to that of the blank without the TAZS layer $\left(8,484 \mathrm{~cd} / \mathrm{m}^{2}, 2.13 \mathrm{~cd} / \mathrm{A}\right)$. Dramatic performance degradation at thicker TAZS $(34 \mathrm{~nm})$ is probably ascribed to imbalanced charges' recombination caused by over-reduction in holes' transport. However, regardless of the 


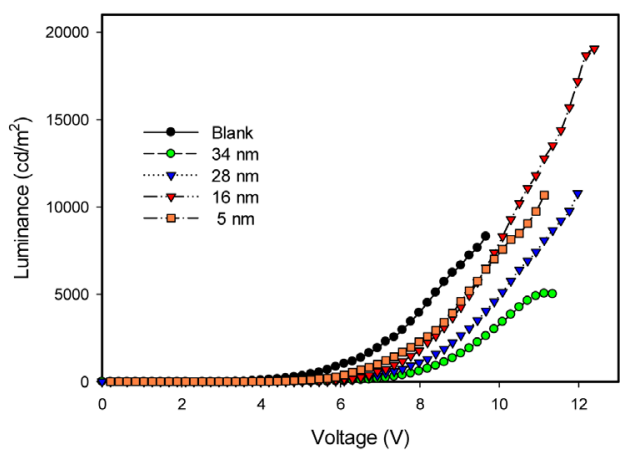

(a)

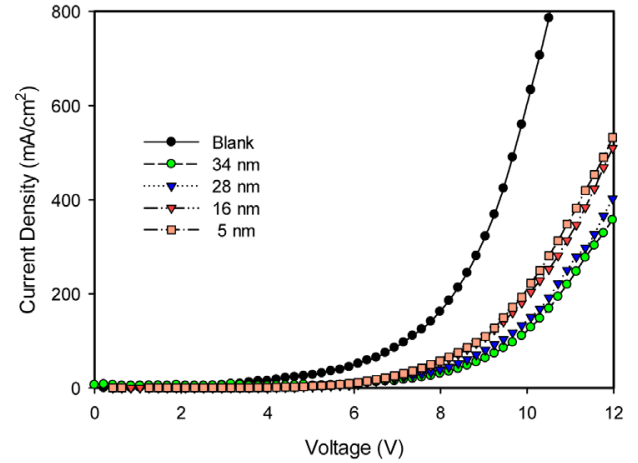

(b)

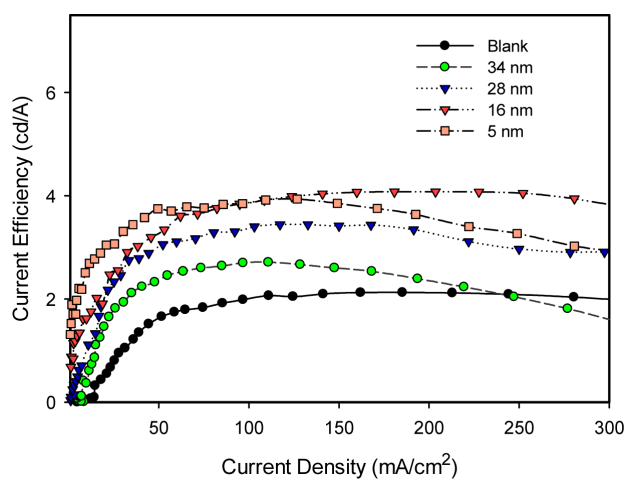

(c)

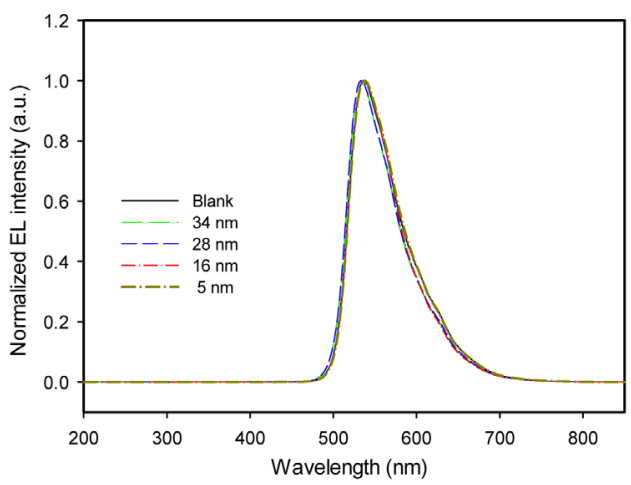

(d)

Figure 7. (a) Luminance versus voltage; (b) Current density versus voltage; (c) Current efficiency versus current density, and EL spectra of PLEDs. Device structure: ITO/PEDO: PSS (40 nm)/TAZS (x nm)/SY (70 nm)/LiF (1 nm)/Al (90 nm). 
Table 4. Optoelectronic properties of PLEDs with hole-buffering TAZS layer ${ }^{\mathrm{a}}$.

\begin{tabular}{cccccc}
\hline Thickness of TAZS & $\begin{array}{c}\mathrm{V}_{\text {on }} \\
(\mathrm{V})^{\mathrm{b}}\end{array}$ & $\begin{array}{c}\mathrm{L}_{\max } \\
\left(\mathrm{cd} / \mathrm{m}^{2}\right)^{\mathrm{c}}\end{array}$ & $\begin{array}{c}\mathrm{CE}_{\max } \\
(\mathrm{cd} / \mathrm{A})^{\mathrm{d}}\end{array}$ & $\begin{array}{c}\mathrm{LPE}_{\max } \\
(\mathrm{lm} / \mathrm{W})^{\mathrm{e}}\end{array}$ & $\begin{array}{c}\mathrm{CIE} \\
(\mathrm{x}, \mathrm{y})^{\mathrm{f}}\end{array}$ \\
\hline None & 3.4 & 8484 & 2.13 & 0.88 & $(0.41,0.57)$ \\
$5 \mathrm{~nm}^{\mathrm{g}}$ & 4.1 & 10,664 & 3.93 & 1.51 & $(0.41,0.57)$ \\
$16 \mathrm{~nm}^{\mathrm{g}}$ & 4.5 & 19,046 & 4.08 & 1.38 & $(0.40,0.58)$ \\
$28 \mathrm{~nm}^{\mathrm{g}}$ & 5.3 & 10,770 & 3.44 & 1.14 & $(0.39,0.58)$ \\
$34 \mathrm{~nm}^{\mathrm{g}}$ & 5.7 & 6574 & 2.71 & 0.88 & $(0.42,0.56)$ \\
\hline
\end{tabular}

${ }^{a}$ Device structure: ITO/PEDOT: PSS $(40 \mathrm{~nm}) /$ TAZS $(\mathrm{x} \mathrm{nm}) / \mathrm{SY}(70 \mathrm{~nm}) / \mathrm{LiF}(1 \mathrm{~nm}) / \mathrm{Al}(90 \mathrm{~nm}){ }^{\mathrm{b}}{ }^{\mathrm{T}}$ urn-on voltage at $10 \mathrm{~cd} / \mathrm{m}^{2} .{ }^{\mathrm{c}}$ Maximum luminance. ${ }^{\mathrm{d}}$ Maximum current efficiency. ${ }^{\mathrm{e}}$ Maximum luminous power efficiency. ${ }^{\text {fThe }} 1931 \mathrm{CIE}$ coordinate at maximum luminance. ${ }^{\mathrm{g}}$ Thickness was measured by alpha-step.

TAZS thickness, the emission spectra remains almost unchanged as shown in Figure 7(d) and in CIE coordinates in Table 4. This indicates that the recombination region of holes and electrons is mainly in the emissive SY layer. Accident exciton formation in TAZS layer near interface will not degrade color purity, because the emission of TAZS is negligible due to fluorescent quenching by induced electron transfer from azomethine groups [28] [29]. To conclude, hole-buffering capability of TAZS layer effectively raise the recombination ratio of carriers in PLEDs to improve carriers' recombination ratio, leading to enhanced device performance.

\section{Conclusion}

We have successfully synthesized a new aromatic 1,2,4-triazolylderivative (TAZS) linked with three peripheral trihydroxy tert-butyl groups via azomethine bond. The TAZS is an amorphous material with thermal decomposition temperature of $264^{\circ} \mathrm{C}$. Moreover, TAZS reveals as homogeneous film by spin-coating process. Insertion of TAZS layer between hole-injecting PEDOT: PSS and emission SY layers dramatically reduces current density of hole-only devices, but only slightly for electron-only devices. Multilayer PLEDs have been successfully fabricated using 5 - $34 \mathrm{~nm}$ spin-coated TAZS as hole-buffer layer (HBL). The PLED with $16 \mathrm{~nm}$ TAZS demonstrates the optimal performance, with maximum luminance and maximum current efficiency of $19,046 \mathrm{~cd} / \mathrm{m}^{2}$ and $4.08 \mathrm{~cd} / \mathrm{A}$, respectively. Both luminance and efficiency are significantly enhanced when compared to the device without HBL $\left(8484 \mathrm{~cd} / \mathrm{m}^{2}, 2.13 \mathrm{~cd} / \mathrm{A}\right)$.

\section{Acknowledgements}

The authors gratefully acknowledge financial support from the Ministry of Science and Technology of Taiwan (MOST106-2221-E-006-209).

\section{Conflicts of Interest}

The authors declare no conflicts of interest regarding the publication of this paper. 


\section{References}

[1] Friend, R.H., Gymer, R.W., Holmes, A.B., Burroughes, J.H., Marks, R.N., Taliani, C., Bradley, D.D.C., Dos Santos, D.A., Bredas, J.L., Logdlund, M. and Salaneck, W.R. (1999) Electroluminescence in Conjugated Polymers. Nature, 397, 121-128. https://doi.org/10.1038/16393

[2] Gustafsson, G., Cao, Y., Treacy, G.M., Klavetter, F., Colaneri, N. and Heeger, A.J. (1992) Flexible Light-Emitting-Diodes Made from Soluble Conducting Polymers. Nature, 357, 477-479. https://doi.org/10.1038/357477a

[3] Burroughes, J.H., Bradley, D.D.C., Brown, A.R., Marks, R.N., Mackay, K., Friend, R.H., Burn, P.L. and Holmes, A.B. (1990) Light-Emitting-Diodes Based on Conjugated Polymers. Nature, 347, 539-541. https://doi.org/10.1038/347539a0

[4] Tsujimura, T. (2017) OLED Display Fundamentals and Applications. Wiley-SID Series in Display Technology, New York. https://doi.org/10.1002/9781119187493

[5] Kamtekar, K.T., Monkman, A.P. and Bryce, M.R. (2010) Recent Advances in White Organic Light-Emitting Materials and Devices (WOLEDs). Advanced Materials. 22, 572-582. https://doi.org/10.1002/adma.200902148

[6] Shinar, J. (2004) Organic Light-Emitting Devices: A Survey. Springer-Verlag, New York. https://doi.org/10.1007/978-0-387-21720-8

[7] Malliaras, G.G. and Scott, J.C. (1998) The Roles of Injection and Mobility in Organic Light Emitting Diodes. Journal of Applied Physics, 83, 5399-5403.

https://doi.org/10.1063/1.367369

[8] Meng, H.-F. and Chen, Y.-S. (2004) Theory of Imbalanced Electron-Hole Transport in Conjugated Polymers. Physical Review B, 70, Article ID: 115208.

https://doi.org/10.1103/PhysRevB.70.115208

[9] Xia, Y.-J., Lin, J., Tang, C., Yin, K., Zhong, G.-Y., Ni, G., Peng, B., Gan, F.-X. and Huang, W. (2006) High-Efficiency Blue-Emitting Organic Light-Emitting Devices with 4,4,',-Tris(N-Carbazolyl)-Triphenylamine as the Hole/Exciton-Blocking Layer. Journal of Physics D: Applied Physics, 39, 4987. https://doi.org/10.1088/0022-3727/39/23/013

[10] Tadayyon, S.M., Grandin, H.M., Griffiths, K., Norton, P.R., Aziz, H. and Popovic, Z.D. (2004) CuPc Buffer Layer Role in OLED Performance: A Study of the Interfacial Band Energies. Organic Electronics, 5, 157-166.

https://doi.org/10.1016/j.orgel.2003.10.001

[11] Lee, S.J., Lee, S.E., Lee, D.H., Koo, J.R., Lee, H.W., Yoon, S.S., Park, J. and Kim, Y.K. (2014) Effect of Broad Recombination Zone in Multiple Quantum Well Structures on Lifetime and Efficiency of Blue Organic Light-Emitting Diodes. Japanese Journal Applied Physics, 53, Article ID:101601. https://doi.org/10.7567/JJAP.53.101601

[12] Sek, D., Siwy, M., Grucela, M., Malecki, G., Nowak, E.M., Lewinska, G., Santera, J., Laba, K., Lapkowski, M., Kotowicz, S. and Schab-Balcerzak, E. (2017) New Anthracene-Based Schiff Bases: Theoretical and Experimental Investigations of Photophysical and Electrochemical Properties. Spectrochimica Acta Part A: Molecular and Biomolecular Spectroscopy, 175, 24-35.

https://doi.org/10.1016/j.saa.2016.12.013

[13] Sek, D., Grucela-Zajac, M., Krompiec, M., Janeczek, H. and Schab-Balcerzak, E. (2012) New Glass Forming Triarylamine Based Azomethines as a Hole Transport materials: Thermal, Optical and Electrochemical Properties. Optical Materials, 34, 1333-1346. https://doi.org/10.1016/j.optmat.2012.02.014

[14] Sęk, D., Lapkowski, M., Dudek, H., Karoń, K., Janeczek, H. and Jarząbek, B. (2012) Optical and Electrochemical Properties of Three-Dimensional Conjugated Triphe- 
nylamine-Azomethine Molecules. Synthetic Metals, 162, 1046-1051. https://doi.org/10.1016/j.synthmet.2012.04.024

[15] Wesley Jeevadason, A., KalidasaMurugavel, K. and Neelakantan, M.A. (2014) Review on Schiff Bases and Their Metal Complexes as Organic Photovoltaic Materials. Renewable \& Sustainable Energy Reviews, 36, 220-227. https://doi.org/10.1016/j.rser.2014.04.060

[16] Abu-Dief, A.M. and Mohamed, I.M.A. (2015) A Review on Versatile Applications of Transition Metal Complexes Incorporating Schiff Bases. Beni-Suef University Journal of Basic and Applied Sciences, 4, 119-133. https://doi.org/10.1016/j.bjbas.2015.05.004

[17] Sánchez, C.O., Bèrnede, J.C., Cattin, L., Makha, M. and Gatica, N. (2014) Schiff Base Polymer Based on Triphenylamine Moieties in the Main Chain. Characterization and Studies in Solar Cells. Thin Solid Films, 562, 495-500.

https://doi.org/10.1016/j.tsf.2014.04.071

[18] Petrus, M.L., Bouwer, R.K.M., Lafont, U., Athanasopoulos, S., Greenham, N.C. and Dingemans, T.J. (2014) Small-Molecule Azomethines: Organic Photovoltaics via Schiff Base Condensation Chemistry. Journal of Materials Chemistry A, 2, 9474-9477. https://doi.org/10.1039/C4TA01629G

[19] Iwan, A., Schab-Balcerzak, E., Grucela-Zajac, M. and Skorka, L. (2014) Structural Characterization, Absorption and Photoluminescence Study of Symmetrical Azomethines with Long Aliphatic Chains. Journal of Molecular Structure, 1058, 130-135. https://doi.org/10.1016/j.molstruc.2013.10.067

[20] Morgan, P.W., Kwolek, S.L. and Pletcher, T.C. (1987) Aromatic Azomethine Polymers and Fibers. Macromolecules, 20, 729-739.

https://doi.org/10.1021/ma00170a006

[21] Kuder, J.E., Gibson, H.W. and Wychick, D. (1975) Linear Free Energy Relations. III. Electrochemical Characterization of Salicylaldehyde Anils. Journal of Organic Chemistry, 40, 875-879. https://doi.org/10.1021/jo00895a013

[22] Guarin, S.A.P., Bourgeaux, M., Dufresne, S. and Skene, W.G. (2007) Photophysical, Crystallographic, and Electrochemical Characterization of Symmetric and Unsymmetric Self-Assembled Conjugated Thiopheno Azomethines. Journal of Organic Chemistry, 72, 2631-2643. https://doi.org/10.1021/jo070100o

[23] Zhou, L., Kwong, C.L., Kwok, C.C., Cheng, G., Zhang, H. and Che, C.M. (2014) Efficient Red Electroluminescent Devices with Sterically Hindered Phosphorescent Platinum (II) Schiff Base Complexes and Iridium Complex Codopant. Chemistry, 9, 2984-2994. https://doi.org/10.1002/asia.201402618

[24] Nishal, V., Singh, D., Kumar, A., Tanwar, V., Singh, I., Srivastava, R. and Kadyan, P.S. (2014) A New Zinc-Schiff Base Complex as an Electroluminescent Material. Journal of Organic Semiconductors, 2, 15-20. https://doi.org/10.1080/21606099.2014.942767

[25] Kathirgamanathan, P., Surendrakumar, Antipan-Lara, J., Ravichandran, R., Chan, Y.F., Arkley, V., Ganeshamurugan, S., Kumaraverl, M., Paramswara, G., Partheepan, A., Reddy, V.R., Bailey, D. and Blake, A.J. (2012) Novel Lithium Schiff-Base Cluster Complexes as Electron Injectors: Synthesis, Crystal Structure, Thin Film Characterisation and Their Performance in OLEDs. Journal of Materials Chemistry, 22, 6104-6116. https://doi.org/10.1039/c2jm15114f

[26] Che, C.M., Kwok, C.C., Lai, S.W., Rausch, A.F., Finkenzeller, W.J., Zhu, N. and Yersin, H. (2010) Photophysical Properties and OLED Applications of Phosphorescent Platinum (II) Schiff Base Complexes. Chemistry, 16, 233-247. 
https://doi.org/10.1002/chem.200902183

[27] Wang, L., Jiao, S., Zhang, W., Liu, Y. and Yu, G. (2013) Synthesis, Structure, Optoelectronic Properties of Novel Zinc Schiff-Base Complexes. Chinese Science Bulletin, 58, 2733-2740. https://doi.org/10.1007/s11434-013-5786-2

[28] Sariciftci, N.S., Smilowitz, L., Heeger, A.J. and Wudl, F. (1992) Photoinduced Electron-Transfer from a Conducting Polymer to Buckminsterfullerene. Science, 258, 1474-1476. https://doi.org/10.1126/science.258.5087.1474

[29] Gupta A. and Kumar, N. (2016) A Review of Mechanisms for Fluorescent “Turn-On” Probes to Detect $\mathrm{Al}^{3+}$ Ions. RSC Advances, 6, 106413-106434. https://doi.org/10.1039/C6RA23682K

[30] Manabe, K., Hu, W., Matsumura, M. and Naito, H. (2003) Transport of Carriers in Organic Light-Emitting Devices Fabricated with a p-Phenylenevinylene-Derivative Copolymer. Journal of Applied Physics, 94, 2024-2027. https://doi.org/10.1063/1.1586964

[31] Steyrleuthner, A., Bange, S. and Neher, D. (2009) Reliable Electron-Only Devices and Electron Transport in $n$-Type Polymers. Journal of Applied Physics, 105, Article ID: 064509. https://doi.org/10.1063/1.3086307 


\section{Supplementary Information}

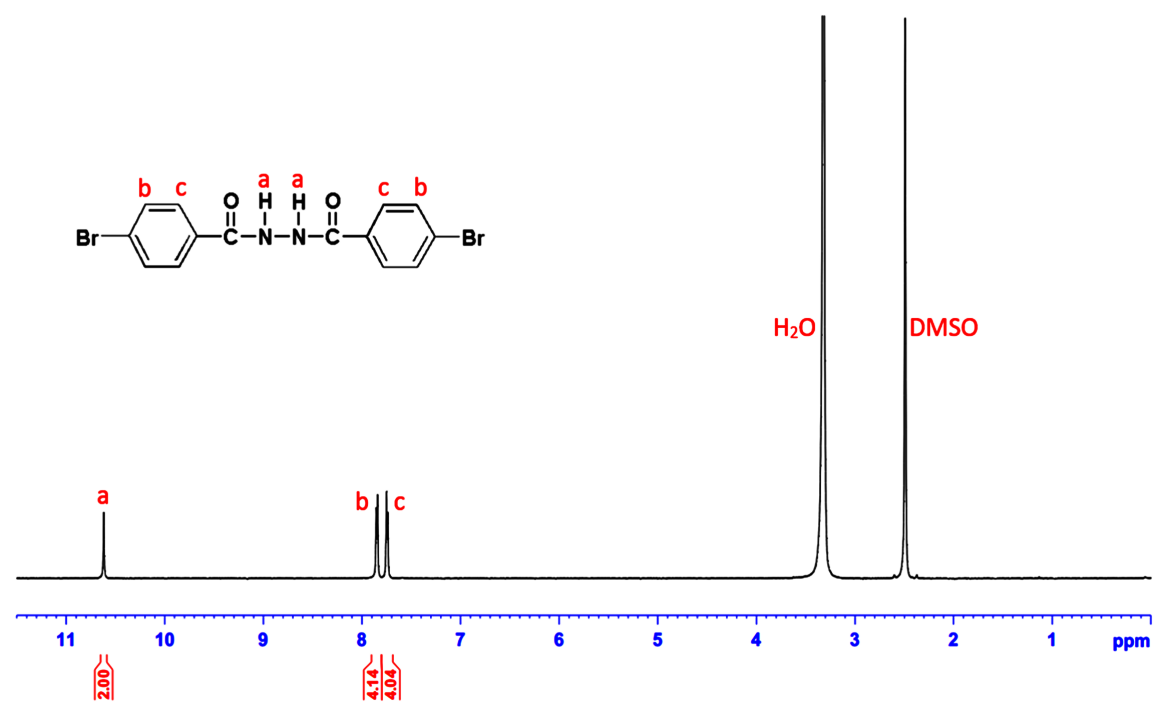

Figure S1. ${ }^{1} \mathrm{H}$ NMR spectrum of compound 2.

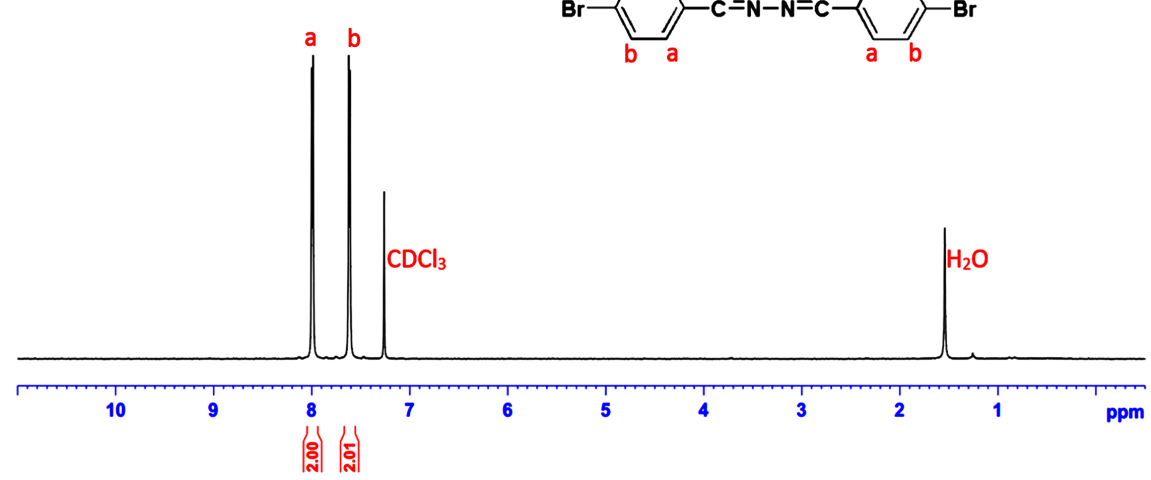

Figure S2. ${ }^{1} \mathrm{H}$ NMR spectrum of compound 3.

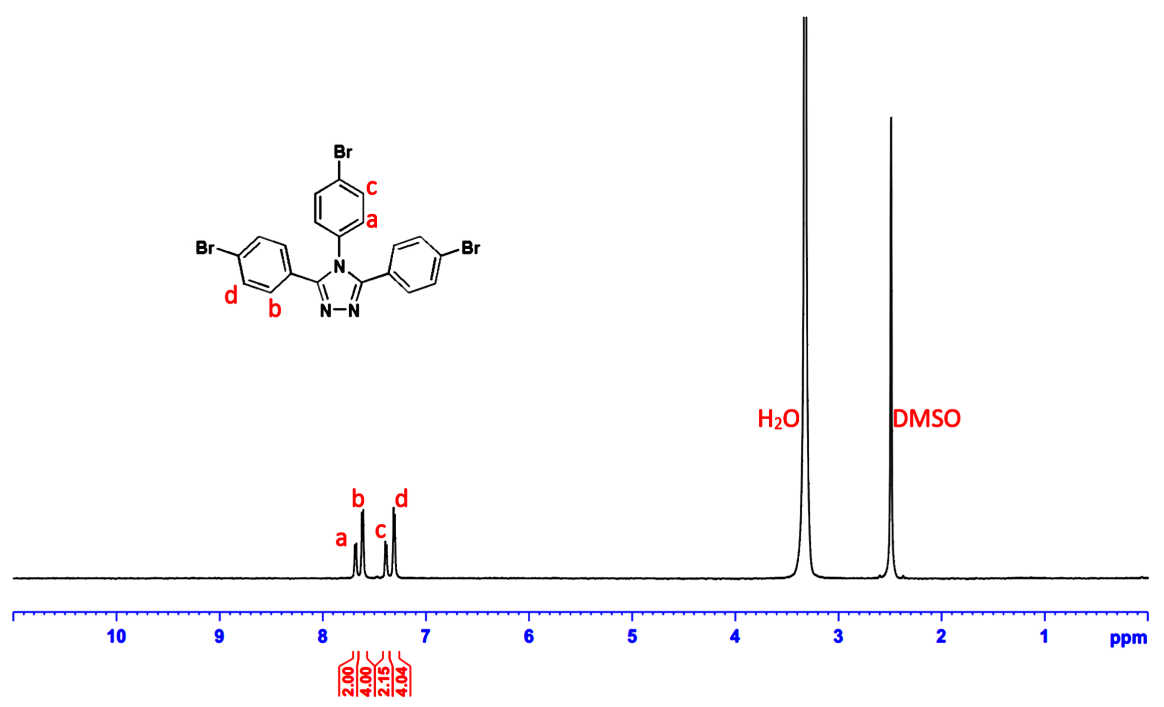

Figure S3. ${ }^{1} \mathrm{H}$ NMR spectrum of compound 4 . 


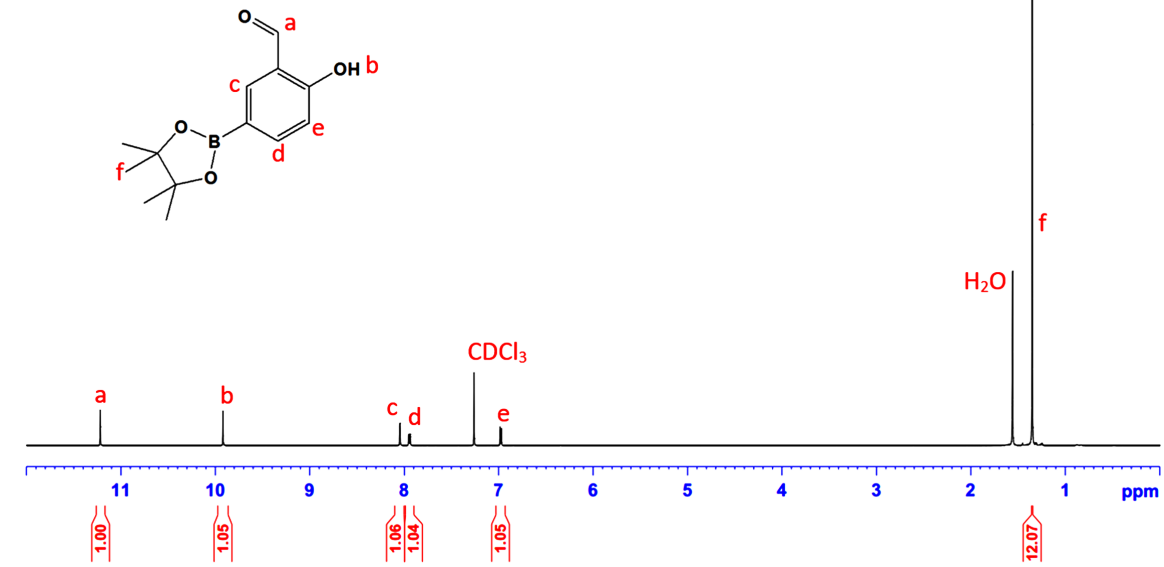

Figure S4. ${ }^{1} \mathrm{H}$ NMR spectrum of compound 5.


Figure S5. ${ }^{1} \mathrm{H}$ NMR spectrum of compound 6.



Figure S6. COSY spectrum of compound 6. 


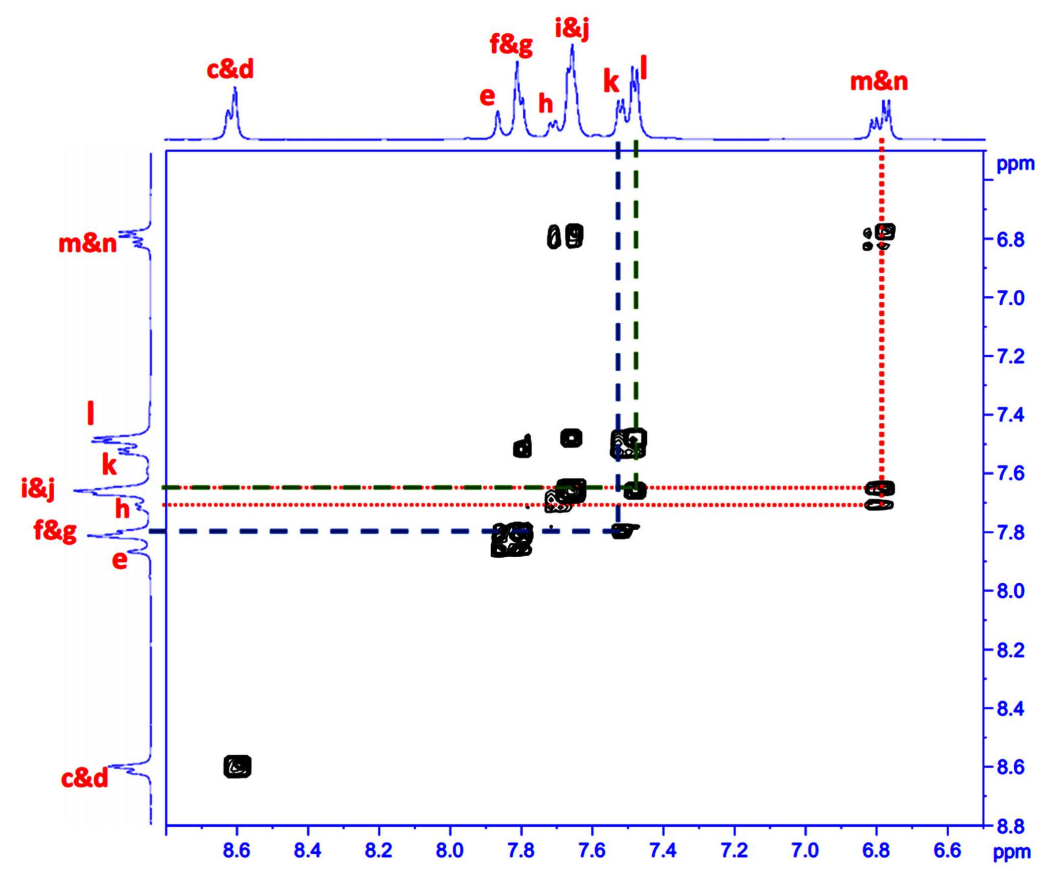

Figure S7. COSY spectrum of TAZS.

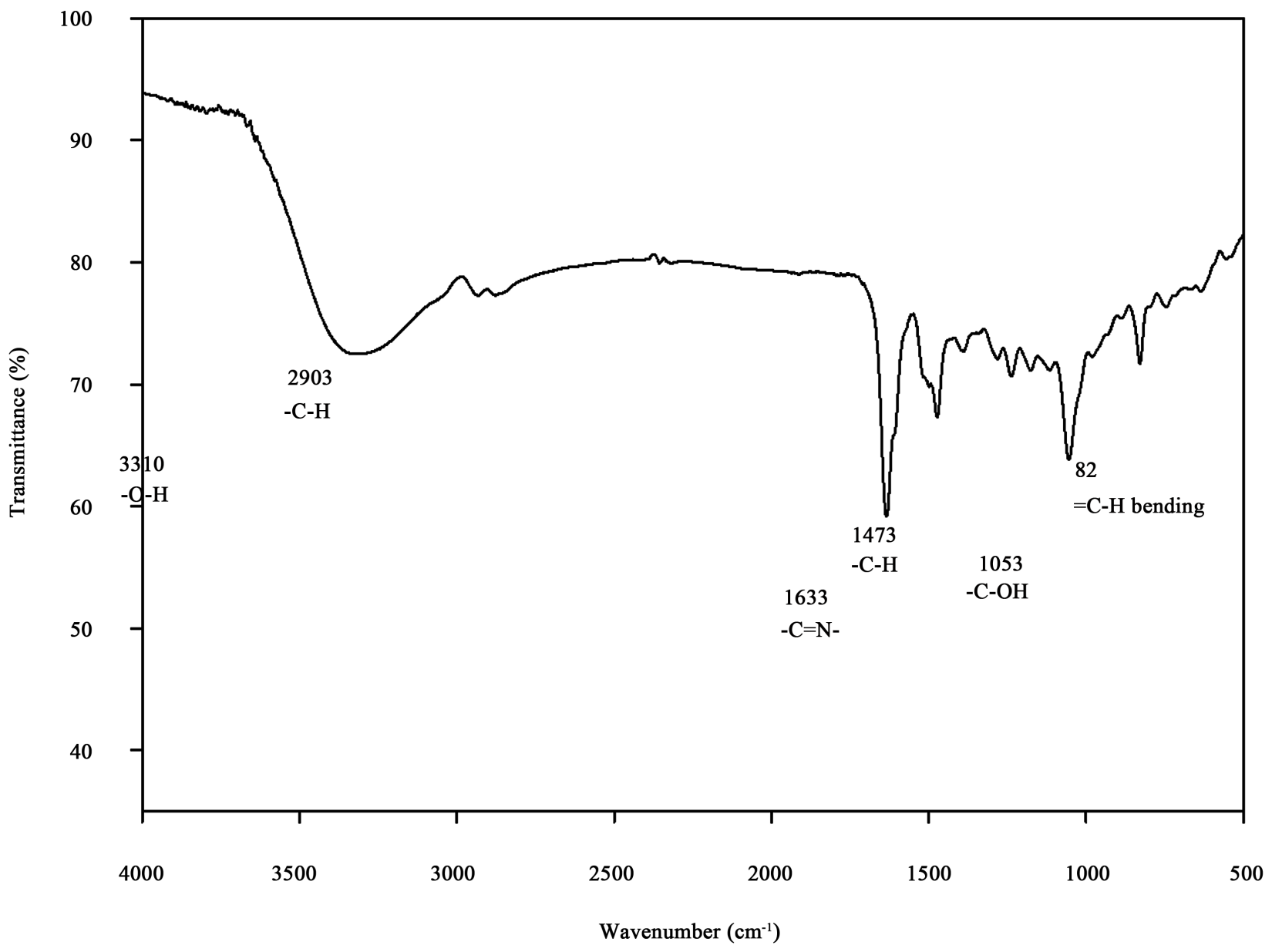

Figure S8. FT-IR spectrum of TAZS. 


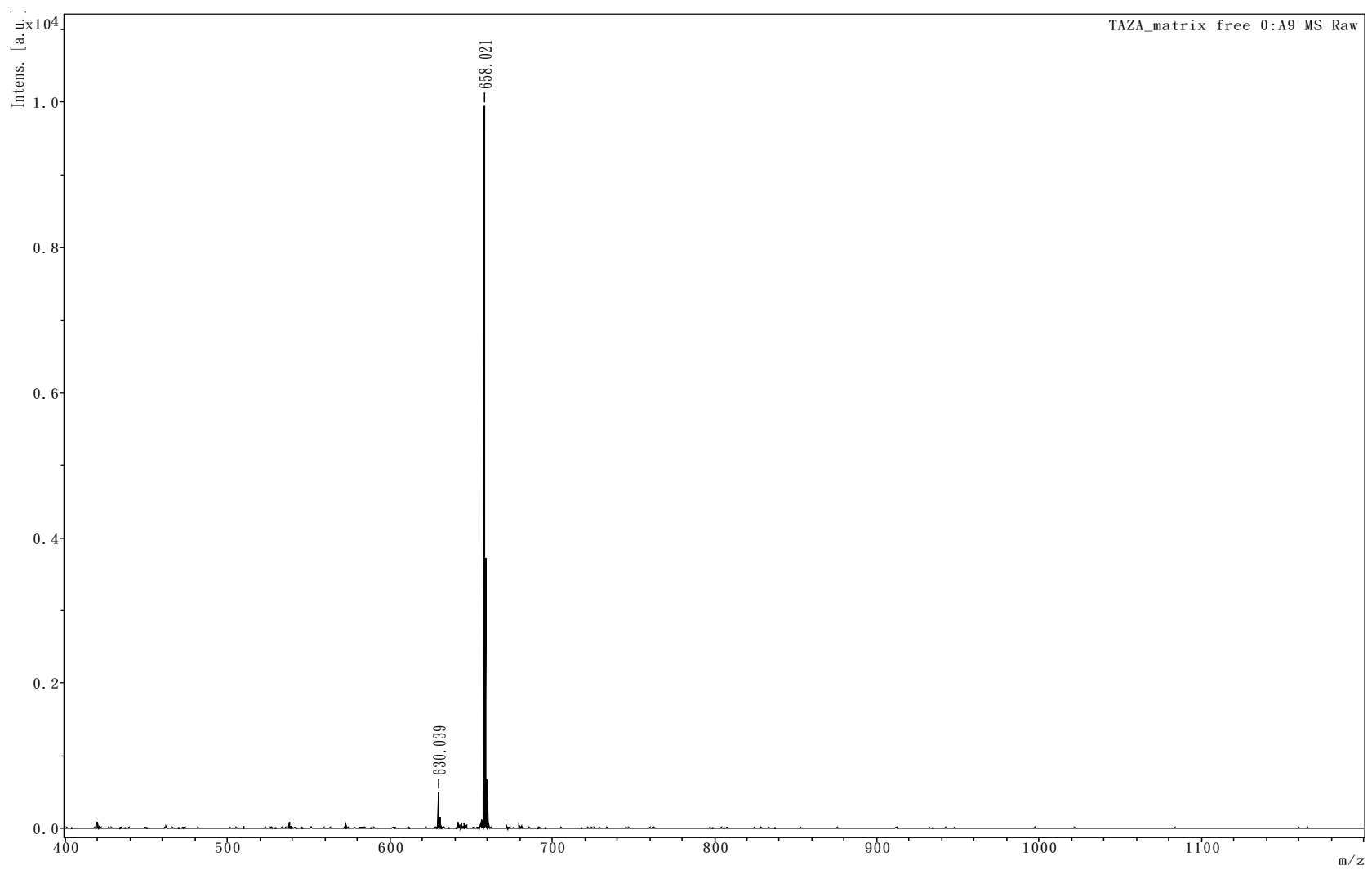

Figure S9. Mass spectrum of compound 6.

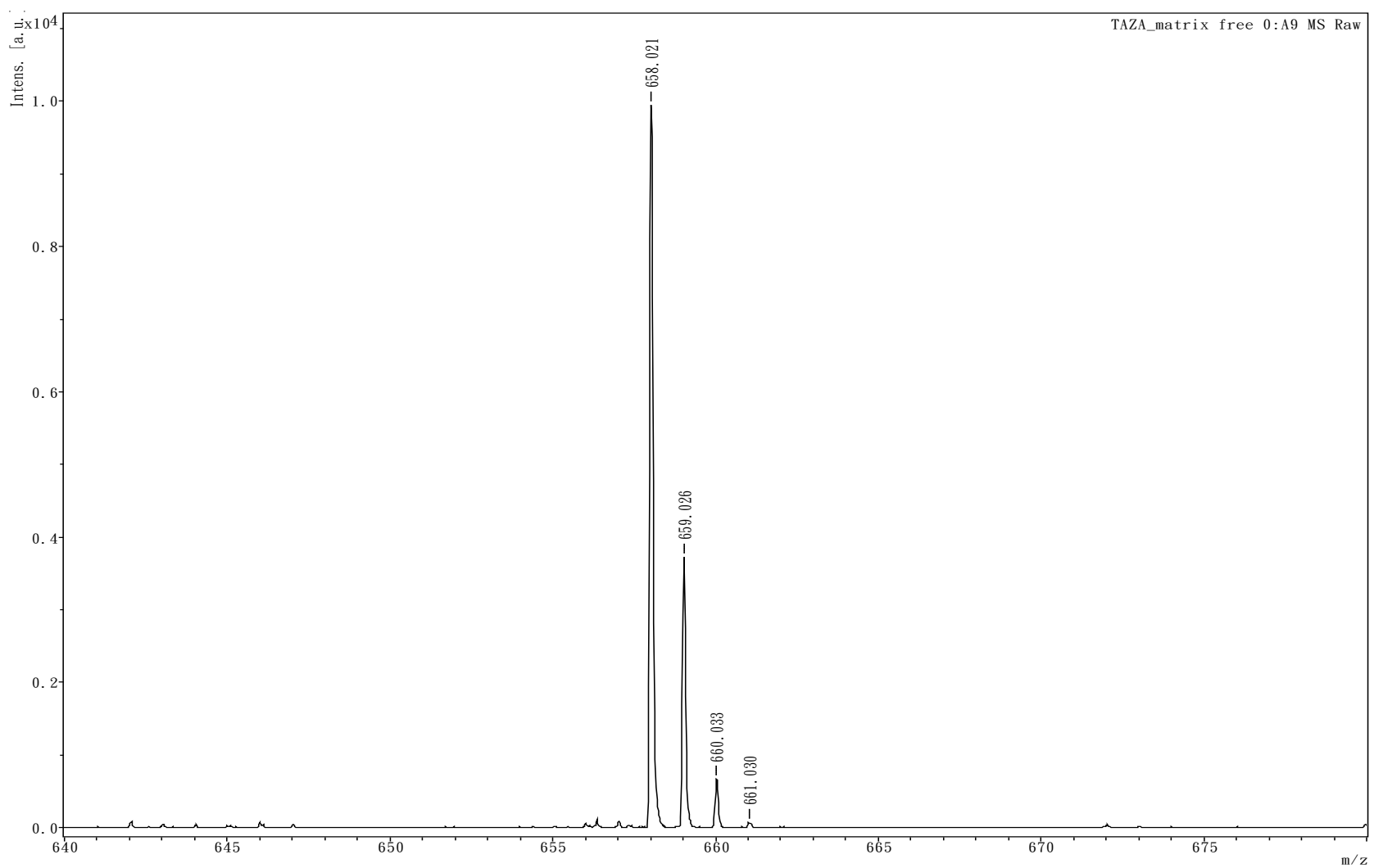

Figure S10. Mass spectrum of compound 6. 


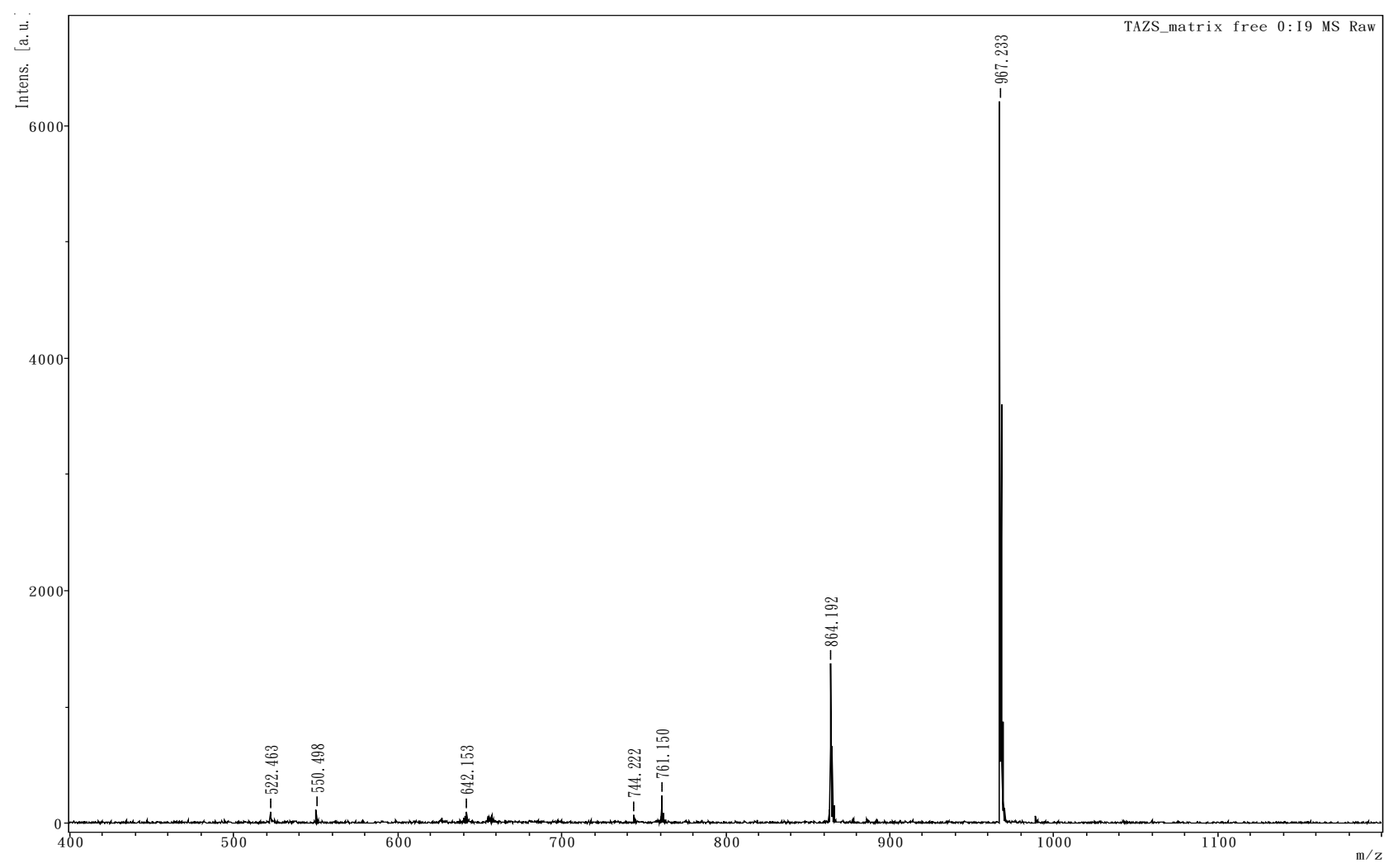

Figure S11. Mass spectrum of TAZS.

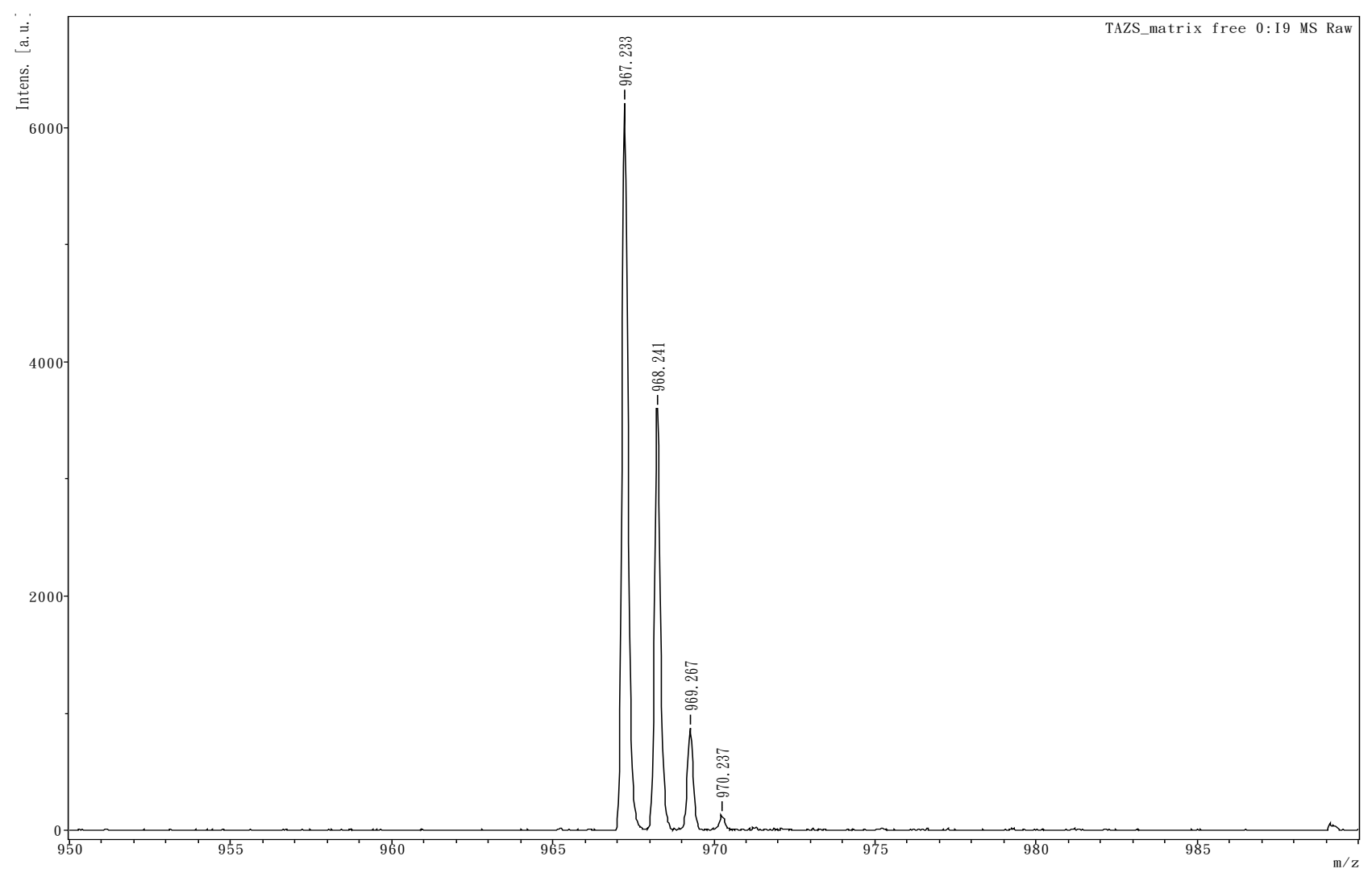

Figure S12. Mass spectrum of TAZS. 


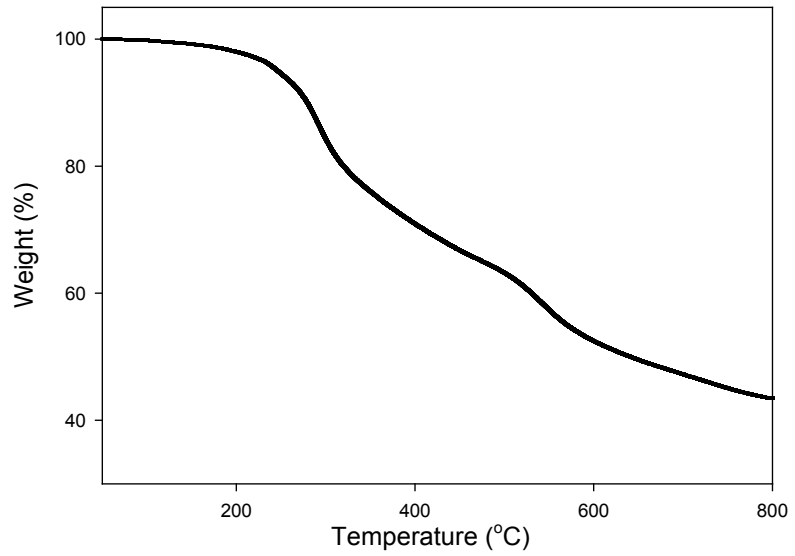

(a)

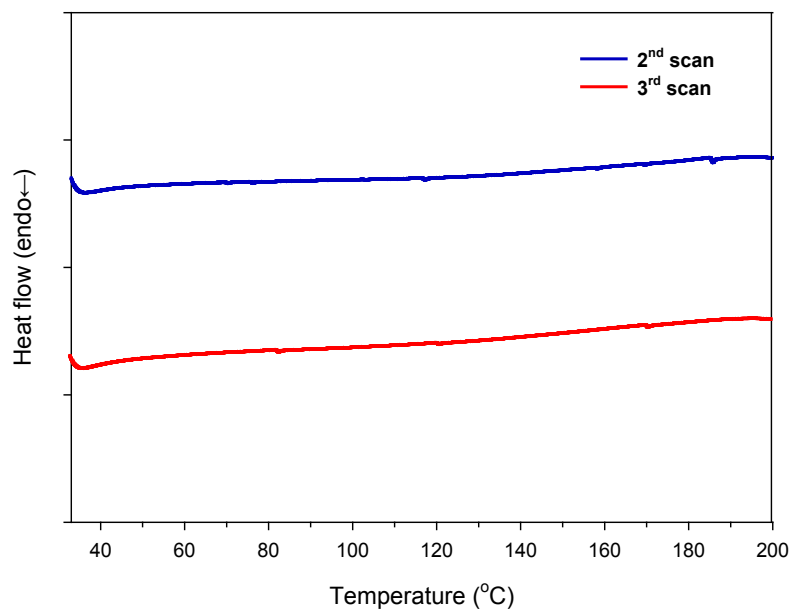

(b)

Figure S13. (a) Thermogravimetric curves of TAZS at heating rate of $10^{\circ} \mathrm{C} / \mathrm{min}$ under nitrogen system. (b) Differential scanning calorimetric curves of TAZS at a heating rate of $10^{\circ} \mathrm{C} / \mathrm{min}$.

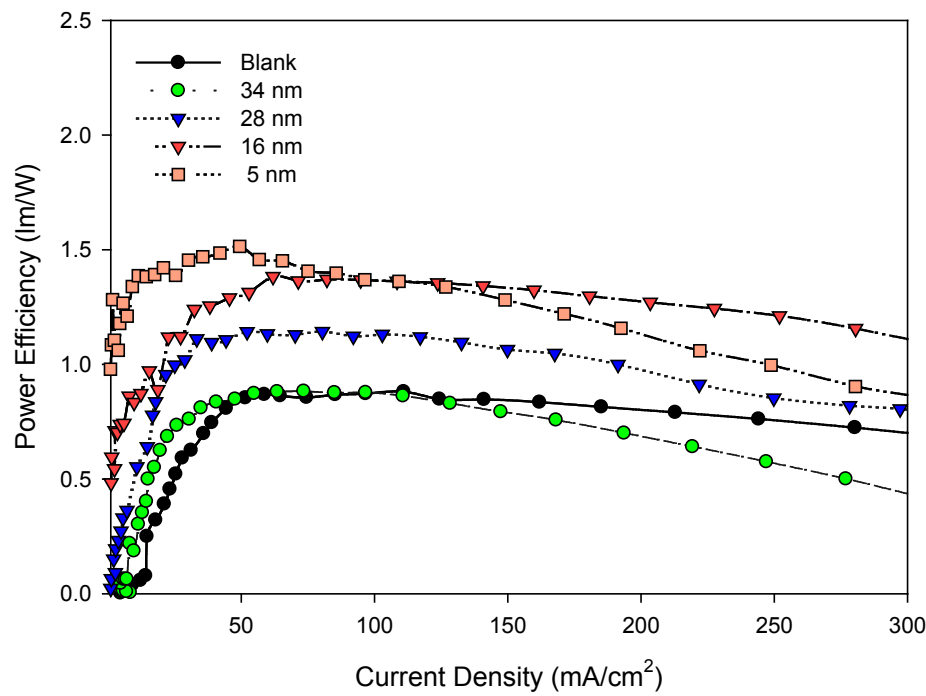

Figure S14. Power efficiency versus current density of PLEDs. Device structure: ITO/PEDOT: PSS (40 nm)/TAZS (x nm)/SY (70 nm)/LiF (1 nm)/Al (90 nm). 